\title{
Prediction of Maternal and Fetoplacental Concentrations of Cefazolin, Cefuroxime and Amoxicillin during Pregnancy using bottom-up Physiologically based Pharmacokinetic Models
}

Khaled Abduljalil*, Jia Ning, Amita Pansari, Xian Pan, Masoud Jamei

Certara UK Limited, Simcyp Division, Sheffield, UK 
Running Title: PBPK Predictions of Maternal and fetoplacental kinetics

Total number of text pages: 23

Total number of figures: 4 figures

Total number of tables: 4 tables

Total word count of the Abstract: 230 words

Total word count of the Introduction: 565 words

Total word count of the Discussion: 1913

\section{*Corresponding Author}

Khaled Abduljalil

Certara UK Limited (Simcyp Division)

Level 2-Acero, 1 Concourse Way,

Sheffield,

S1 2BJ,

United Kingdom

$\mathrm{t}:+44(0) 1144600150$

f: $+44(0) 1144785600$

Khaled.Abduljalil@certara.com

Keywords: Pregnancy, Fetus, Placenta, PBPK, Pharmacokinetics, Renal clearance, Cefuroxime, Cefazolin, Amoxicillin

Abbreviations: PBPK: Physiologically based pharmacokinetics, GWs: Gestational weeks, FA: Fetal age, GFR: glomerular filtration rate, HBD: Hydrogen bond doner, PSA: Polar surface area 


\section{Abstract}

Concerns over maternal and fetal drug exposures highlights the need for a better understanding of drug distribution into the fetus through the placental barrier. This study aimed to predict maternal and fetal drug disposition using physiologically based pharmacokinetic (PBPK) modelling. The detailed maternal-placental-fetal PBPK model within the Simcyp Simulator V20 was used to predict the maternal and fetoplacental exposure of cefazolin, cefuroxime, and amoxicillin during pregnancy and at delivery. The mechanistic dynamic model includes physiological changes of the maternal, fetal, and placental parameters over the course of pregnancy. Placental kinetics were parametrized using permeability parameters determined from the physicochemical properties of these compounds. Then, the PBPK predictions were compared to the observed data.

Fully bottom-up feto-placental PBPK models were developed for cefuroxime, cefazolin, and amoxicillin without any parameter fitting. Predictions in non-pregnant and in pregnant subjects fall within 2-fold of the observed values. Predictions matched observed PK data reported in 9 maternal (5 fetoplacental) studies for cefuroxime, 10 maternal (5 fetoplacental) studies for cefazolin, and 6 maternal ( 2 fetoplacental) studies for amoxicillin. Integration of the fetal and maternal system parameters within PBPK models, together with compound-related parameters used to calculate placental permeability facilitates and extends the applications of the maternal-placental-fetal PBPK model. The developed model can also be used for designing clinical trials and prospectively use for maternal/fetal risk assessment following maternally administered drugs or unintended exposure to environmental toxicants. 


\section{Significance Statement}

This study investigates the performance of an integrated maternal-placental-fetal PBPK model to predict maternal and fetal tissue exposure of renally eliminated antibiotics that cross the placenta through a passive diffusion mechanism. The transplacental permeability clearance were predicted from the drug physicochemical properties. Results demonstrate that the PBPK approach can facilitate the prediction of maternal and fetal drugs exposure simultaneously at any gestational age to support its use in the maternal/fetal exposure assessments. 


\section{Introduction}

Various physiological and biochemical changes occur during pregnancy can affect pharmacokinetics (PK) of administered compounds (Abduljalil et al., 2020c). Currently, most drugs carry warnings or contraindications for their use during pregnancy. Obstetricians frequently prescribe drugs for indications other than those on the product label and this unlicensed or off-labelled use may be necessary if the clinical need cannot be met by licensed medicines. Such use should be supported by appropriate evidence which balances benefits and risks associated with maternal-fetal drug exposure (Rayburn and Farmer, 1997).

Approximately one in four women will be prescribed an antibiotic during pregnancy, accounting for nearly $80 \%$ of prescription medications in pregnant women (Bookstaver et al., 2015). While many antibiotics have been reported to be safe such as penicillins and cephalosporines, there are some antibiotics that should be avoided entirely during pregnancy (Muanda et al., 2017). Different antibiotics can cross the placenta and reach the fetus achieving comparable fetal exposures to the mother (Pacifici, 2006; Viel-Theriault et al., 2019).

Traditionally the extent of the drug passage through the placenta is assessed by comparing the drug concentration in the umbilical cord at birth to the maternal drug concentration, however such measurements are still challenging because only one sample can be obtained per subject within short time frame and the sampling time is relative to the last maternal dose taken. Sampling placenta, fetal organs or systemic circulation during pregnancy for PK evaluation can be challenging and unethical. Experimentally, fetal drug exposure remains difficult to quantify, as the fetus and placenta are not readily accessible for sampling until 
delivery. Various animal models have been used to study placental drug transfer, but data are of poor translational value due to interspecies variability in placental types and structures (Schmidt et al., 2015; Bouazza et al., 2019). On the other hand, an ex vivo human placenta perfusion experiment that uses a single placental cotyledon has shown to be a useful model for studying the transplacental passage of various drugs (Bouazza et al., 2019).

Pregnancy PBPK models that incorporate adequately detailed maternal and fetal physiological parameters are suitable tools that can facilitate the assessment of fetal exposure when placental kinetics are also integrated in the model (De Sousa Mendes et al., 2017; Schalkwijk et al., 2018; Bouazza et al., 2019). Applications of PBPK models to describe fetal exposure are increasing and have been published for many drugs, including emtricitabine, tenofovir, nevirapine, midazolam, theophylline, darunavir, dolutegravir, zidovudine, and acetaminophen (see (Abduljalil and Badhan, 2020)). In most of these examples, transplacental transfer parameters were estimated from the ex vivo human placenta perfusion experiments and were then integrated within the pregnancy PBPK models using appropriate scaling from a single cotyledon to the whole placenta. Those models included at least one compartment to reflect the anatomy of the fetus. While majority of drugs have not been studied using the placental ex vivo perfusion, it is of interest to develop a predictive algorithm to allow prediction of placental pharmacokinetic parameters, mainly passive diffusion across both sides of the placenta.

The aim of this study is to use the multi-compartmental feto-placental PBPK model within the Simcyp Simulator V20 to assess the possibility of predicting the fetal exposure using physicochemical properties of three mainly renally cleared antibiotics, cefuroxime, cefazolin, and amoxicillin. These compounds were chosen due to observed data availability. 
PBPK predictions at different time points during gestation were compared to the clinically observed data.

\section{Materials and Methods}

General Settings: The pregnancy model within the Simcyp Simulator V20 was used for all predictions in the current study. The pregnancy model accounts for physiological parameters inter-individual variability and their changes during the whole gestational period. Growth or decline of the physiological parameters during pregnancy are incorporated in the model as continuous functions to allow predictions at different gestational ages. The model considers the continuous change of all physiological and biological parameters simultaneously over time and within each subject to account for any time-varying covariates.

The model structure includes a multi-compartment fetal PBPK model coupled with the maternal PBPK model via a permeability-limited placenta model. It includes previously reported physiological changes that occur during pregnancy including maternal (Abduljalil et al., 2012) and fetal physiology (Abduljalil et al., 2018; Abduljalil et al., 2019; Abduljalil et al., 2020a; Abduljalil et al., 2021). A basic perfusion-limited version of a PBPK model consisting of 14 compartments representing various fetal tissues was linked to the Simcyp maternal full-PBPK model via the placenta, which in turn was represented by 3-compartments (Fig. 1). Amniotic fluid is modelled using a single compartment. Previously published nonlinear differential equations describing the structure of the model, with its code, for the fetus, placenta and amniotic fluid were used for the model building (Zhang et al., 2017). These equations are based on the mass conservation law describing the changes in drug 
concentration over time after maternal drug administration. In the current study, the model however has been further expanded to include 8 additional fetal tissues, namely, spleen, pancreas, muscle, bone, adipose, heart, lung, and skin. Physiological parameters required for fetal PBPK model specifications and their changes during pregnancy were taken from a recent series of published meta-analyses of physiological, biological and anatomical measurements on total body weight, height, surface area and gross body composition (Abduljalil et al., 2018), organ volumes and compositions (Abduljalil et al., 2019), blood and binding components (Abduljalil et al., 2020a) and organ blood flows (Abduljalil et al., 2021). Equations describing longitudinal changes in fetal physiological parameters values from these references were incorporated into the fetal PBPK model and coupled to the maternal PBPK model within the Simulator.

The amniotic fluid is mainly composed of water and its volume increases with pregnancy progression according to our previously published data (Abduljalil et al., 2012). The model assumes that the administered drug reaches the amniotic fluid via fetal renal clearance and leaves the amniotic fluid back into the fetal circulation via fetal swallowing activity and intra-membranous diffusion.

\section{Model building}

For all evaluated compounds, distribution was defined using a full PBPK distribution model that accounts for different tissue volumes and flow rates. Drug tissue to plasma partition ratios (Kps) were predicted within the Simulator for these compounds using the Rodgers and Rowland method (Rodgers and Rowland, 2006) (see below for more detail). Elimination of the drugs were described using the mechanistic kidney model (MechKiM) to account for 
renal transporters kinetics (Neuhoff et al., 2013). No fetal hepatic clearance was assumed for these compounds.

Before predicting the drug kinetics during pregnancy, all compound PBPK models were first built and verified for their performances in non-pregnant population as described earlier (Abduljalil et al., 2020c). Once the PBPK model adequately predicted the drug kinetics in non-pregnant subjects, the settings were retained to predict the drug kinetics in pregnant women at different gestational weeks. Predictions in all cases were performed via matched virtual population demographics, clinical trial simulation settings/designs to the original studies. Predicted PK profiles and PK parameters were compared with different sets of clinical observations available in the literature. Default demographics and age range were used when corresponding data were not provided in the original paper.

No data from ex vivo human placenta perfusion experiment were available, for the three compounds of interest here, therefore to parametrize the full feto-placental model, the compound Hydrogen bond doner (HBD) and Polar surface area (PSA) are used to predict the transplacental passive permeability of cefuroxime using Eq. 1 (Yang et al., 2007):

$$
P_{e f f}\left(10^{-4} \mathrm{~cm} / \mathrm{s}\right)=10^{\wedge}(1.454-0.011 P S A-0.278 \mathrm{HBD}) \quad \text { Eq. } 1
$$

Then the placenta diffusion clearance $\mathrm{CL}_{\mathrm{PD}}$ was calculated as follows (Eq. 2):

$$
C L_{P D}(L / h / m L \text { of Placenta })=P_{\text {eff }}\left(\frac{3.6 \text { PVSA }}{\text { Vol.Placenta }}\right) \quad \text { Eq. } 2
$$

Where PSA is polar surface area and $H B D$ is the Hydrogen bond donor of the compound, while PVSA is the placenta villus surface area at term (PVSA $=11 \mathrm{~m}^{2}$ (Boyd, 1984; Teasdale and Jean-Jacques, 1985; Mayhew, 2001)), Vol.Placenta is the placenta volume at term in $\mathrm{mL}$ 
$(665 \mathrm{~mL})$ and 3.6 is a unit conversion scalar. The placental permeability clearance input in the model is in $\mathrm{mL} / \mathrm{min} / \mathrm{mL}$ of placental volume unit. This approach is useful to allow scaling the permeability to early gestational weeks based on the placental volume.

At term, the fetus swallows on average $400 \mathrm{~mL}$ of amniotic fluid per day (Blackburn, 2007). Therefore, this value was used to describe the swallowing activity clearance in the model (i.e., $\mathrm{CL}_{\text {swallowing }}(\mathrm{L} / \mathrm{h} / \mathrm{kg}$ fetal weight $)=0.00476 \mathrm{~L} / \mathrm{h} / \mathrm{kg}$ fetal weight). Additionally, the intramembranous pathway transfers about $200-500 \mathrm{~mL} /$ day of fluid and solutes from the amniotic cavity to the fetal circulation across the amniotic membranes (see (Underwood et al., 2005)). This flow has been calculated using $350 \mathrm{~mL} /$ day and normalized to $3.5 \mathrm{~kg}$ of fetal body weight at term, i.e., $\mathrm{CL}_{\text {intramembranous }}=0.00417 \mathrm{~L} / \mathrm{h} / \mathrm{kg}$ ). The combined fetal $\mathrm{CL}_{\text {swallowing }}$ and $\mathrm{CL}_{\text {intramembranous }}\left(\mathrm{CL}_{\text {swallowing }}+\mathrm{CL}_{\text {intramembranous }}=0.00893 \mathrm{~L} / \mathrm{h} / \mathrm{kg}\right)$ was considered as a system parameter and incorporated int the model for all compounds. The $\mathrm{CL}_{\text {intramembranous }}$ is assumed to be a bidirectional flow and added to the calculated fetal renal clearance $\left(f e t a l C L_{R}\right)$ as they both use the same deriving concentration, i.e., fetal systemic venous concentration (see supplementary material in (Zhang and Unadkat, 2017)). The fetal $C L_{R}$ itself was calculated with reference to an adult GFR of $121 \mathrm{~mL} / \mathrm{min}$ (Rhodin et al., 2009) according to the following equation (Eq. 3) and assuming a fetal bodyweight of $3.5 \mathrm{~kg}$ at term:

fetal $C L_{R}(L / h / k g)=\left(\frac{\text { Adult } C L_{R}(L / h)}{\text { Fetal Bodyweight }(K g)}\right) \cdot\left(\frac{\text { Urine Flow }(\mathrm{mL} / \mathrm{min})}{\text { Adult } G F R(\mathrm{~mL} / \mathrm{min})}\right) \quad$ Eq. 3

The fetal urine flow rate at term was about $1.39 \mathrm{~mL} / \mathrm{min}$ (weighted mean of observations from (Lee et al., 2007; Touboul et al., 2008; Maged et al., 2014)). 


\section{Cefuroxime}

Cefuroxime is a second generation of cephalosporin antibiotic, for treatment of several infections during pregnancy (Alrammaal et al., 2019). Cefuroxime is primarily cleared by kidney as unchanged drug (about $97.3 \%$ of the administered dose) and its renal clearance correlates well with urine flow and creatinine clearance in normal as well as in impaired renal function (van Dalen et al., 1979). Both glomerular filtration and tubular excretion are involved with about $40-49 \%$ of the renal excretion of cefuroxime via tubular excretion (Gower and Dash, 1977; Verhagen et al., 1994). Different studies investigated cefuroxime kinetics during pregnancy and its passage across the placenta during pregnancy (Bousfield et al., 1981; Craft et al., 1981; Philipson and Stiernstedt, 1982; Roumen et al., 1990; De Leeuw et al., 1993; Holt et al., 1993; Holt et al., 1994).

\section{Model building:}

A PBPK model for cefuroxime for non-pregnant population has already published and verified after ascending intravenous (IV) doses in healthy male subjects (Hsu et al., 2014). In that model, due to lack of data, cefuroxime was assumed to reach the kidney cells through an active process and hence described using a generic basolateral transporter. Once the drug entered the renal cells it is pumped out of the cells into the urine via the MRP4 transporter (see (Hsu et al., 2014)). The original model inputs were used in the current work and expanded to intramuscular (IM) administration with first order absorption rate constant of $1.2(30 \% \mathrm{CV})$ and complete absorption, fa $=1(10 \% \mathrm{CV})$ to describe observed data after 750mg intramuscular dose (O'Callaghan and Harding, 1977). The list of the model inputs is 
given in the electronic supplementary materials (ESM) in Table S1. Predicted exposure in the non-pregnant populations were compared to the observed data.

To extend the non-pregnant cefuroxime PBPK model to predict kinetics during pregnancy, the pregnancy population was used and the permeability-limited placenta model together with the full PBPK fetal model were selected. Calculating cefuroxime placental permeability from HBD and PSA and scaling it up to the placenta (Eq. 1 and Eq. 2) resulted in $\mathrm{CL}_{\mathrm{PD}}$ of $0.0016 \mathrm{~L} / \mathrm{h} / \mathrm{mL}$ placenta (at term). This value was used as diffusion clearances at both sides of the placenta. Based on adult cefuroxime $\mathrm{CL}_{R}$ of $3.5 \mathrm{~L} / \mathrm{h}$ (Hsu et al., 2014), the resulted fetal cefuroxime $\mathrm{CL}_{\mathrm{R}}$ according to Eq. 3 was $0.0390 \mathrm{~L} / \mathrm{h} / \mathrm{kg}$. as mentioned earlier, the $\mathrm{CL}_{\text {intramembranous }}$ is a bidirectional flow, hence the combined fetal $\mathrm{CL}_{\mathrm{R}}+\mathrm{CL}_{\text {intramembranous }}=0.043$ $\mathrm{L} / \mathrm{h} / \mathrm{kg}$ was incorporated in the model before executing the simulations. Cefuroxime is known for its renal toxicity in human and mice data indicated that the drug reach similar concentration in kidney as in the systemic circulation (Hvidberg et al., 2000). While the drug concentration in the maternal kidney is described mechanistically using the MechKiM model, the fetal Kp for the kidney was set to 1 . All other fetal tissue-to-plasma partition coefficients (Kps) were predicted within the Simulator using the Rodgers and Rowland method (Rodgers and Rowland, 2006) without any adjustment to the calculated tissue Kps.

Predicted exposure in the pregnant population were compared to the observed data. The following virtual trial designs were used to predict cefuroxime in pregnant subjects after maternal administration:

Trial design P1: Single IV bolus of $750 \mathrm{mg}$ of cefuroxime given over a period of $1 \mathrm{~min}$ (Philipson and Stiernstedt, 1982); 20 trials of 7 pregnant women aged 20-45 years (default) at $11-35 \mathrm{GWs}$. 
Trial design P2: Single IV bolus of $750 \mathrm{mg}$ of cefuroxime given over a period of $1 \mathrm{~min}$ (Philipson and Stiernstedt, 1982); 20 trials of 7 pregnant women aged 20-45 years at 37-42 GWs.

Trial design P3: Single IV bolus of $750 \mathrm{mg}$ of cefuroxime given over a period of $3 \mathrm{~min}$ (Holt et al., 1994); 20 trials of 26 pregnant women between 35-40 GWs and aged 20-45 years.

Trial design P4: Single IV bolus of $1500 \mathrm{mg}$ of cefuroxime given over a period of $3 \mathrm{~min}$ (Holt et al., 1994); 20 trials of 13 pregnant women between 38-40 GWs and aged 20-45 years.

Trial design P5: Single IV bolus of $750 \mathrm{mg}$ of cefuroxime given over a period of $3 \mathrm{~min}$ (Holt et al., 1993); 20 trials of 78 pregnant women between $38-40 \mathrm{GWs}$ and aged $20-45$ years.

Trial design P6: Single IV bolus of $750 \mathrm{mg}$ of cefuroxime given over a period of $1 \mathrm{~min}$ (Bousfield et al., 1981); 20 trials of 10 pregnant women aged 18-32 years at term (40 GWs).

Trial design P7: An IV bolus of $750 \mathrm{mg}$ of cefuroxime given over a period of $1 \mathrm{~min}$ followed by similar dose after $4 \mathrm{hr}$ (Bousfield et al., 1981); 20 trials of 10 pregnant women aged 18-32 years at term (40 GWs).

Trial design P8: Single IM injection of 750 mg cefuroxime (Craft et al., 1981); 20 trials of 22 pregnant women at term (40 GWs) and aged $18-45$ years.

Trial design P9: Multiple IV infusions of $1500 \mathrm{mg}$ of cefuroxime given over a period of 10 min every 8 h (Roumen et al., 1990; De Leeuw et al., 1993); 20 trials of 10 pregnant women between $27-35 \mathrm{GWs}$ and aged $23-45$ years.

Trial design P10: Single IV bolus of $750 \mathrm{mg}$ of cefuroxime given over a period of $1 \mathrm{~min}$ (Takase et al., 1979); 10 trials of 29 pregnant Japanese women aged 20-45 years at term 40 
GWs (use of sim-pregnancy population file with Japanese female's bodyweight/height and kidney parameters)

\section{Cefazolin}

Cefazolin is commonly prescribed as a prophylactic antimicrobial agent for a variety of surgical interventions, including caesarean section. The drug is administered via intravenous or intramuscular routes. Different clinical studies have evaluated the pharmacokinetics of cefazolin during late pregnancy and have reported the concentrations in maternal circulation, the umbilical cord and amniotic fluid (Bernard et al., 1977; Philipson et al., 1987; Brown et al., 1990; Fiore Mitchell et al., 2001; Allegaert et al., 2009; Elkomy et al., 2014; van Hasselt et al., 2014; Grupper et al., 2017; Kram et al., 2017).

Model building: A PBPK model for cefazolin was built using published physicochemical properties and experimental data as well as predictive algorithms within the Simulator. In brief, the distribution was described using the full PBPK distribution model with the tissue to plasma partition coefficients being predicted using the Rodgers and Rowland method (Rodgers and Rowland, 2006) with a global Kp scalar of 0.7 to match observed data after 1000mg intravenous dose (Rattie and Ravin, 1975). Cefazolin elimination was described using the MechKim and additional non-specific hepatic metabolism. The elimination through the kidney was described using permeability clearance on both sides of the renal cells and active transporters at the proximal tubules using the basolateral Organic anion transporters OAT1 and OAT3 uptake transporters (Mathialagan et al., 2017) as well as the apical MRP4 efflux transporter ( $\mathrm{Ci}$ et al., 2007). The model then extended to intramuscular route using a 
reported intramuscular absorption rate constant of $1.01 / \mathrm{h}$ (Scheld et al., 1981). See supplementary materials (Table S1) for the list of the model input. Predicted exposure in the non-pregnant and pregnant populations were compared to the observed data.

To extend the model to predict cefazolin disposition during pregnancy, the pregnancy population was used using the permeability-limited placenta model and the full PBPK fetal model being selected. A recent study reported that the renal OAT3 activity increased by approximately 2.2, 1.7 and 1.3-fold during the 1st, 2 nd and 3rd trimester, respectively (Peng et al., 2021). These data were described using the following function:

$$
\text { Renal OAT3 } 3_{\text {pregnancy }}=1 *\left(1+0.195 * G W-0.0093 * G W^{2}+0.0001154 G^{3}\right) \quad \text { Eq. } 4
$$

Where GW is the gestational week. This equation was added to the model to predict renal clearance during pregnancy at any gestational week. While no informative data could be found to describe the longitudinal changes in renal OAT1 and MRP4, transporters during pregnancy, the non-pregnant status retained for these two transporters.

Few reports have documented rapid placental passage of intravenously administered cefazolin to umbilical cord blood and amniotic fluid (Philipson et al., 1987; Allegaert et al., 2009; Elkomy et al., 2014; van Hasselt et al., 2014). These studies indicated that cefazolin can readily cross the placenta, however no data from an ex vivo human placenta perfusion experiment were available. For parametrizing the full feto-placental model, the compound HBD and PSA were used to predict the transplacental passive permeability of cefazolin as explained earlier for cefuroxime. This resulted in placental $C_{P D}$ clearance value of 0.0012 $\mathrm{L} / \mathrm{h} / \mathrm{mL}$ of placenta. This value was then applied to both the maternal-faced (CLPDM) and fetal-faced ( $\left.C L_{P D F}\right)$ clearances of the placenta. 
Fetal cefazolin renal clearance was calculated from cefazolin renal clearance value in adult, as described earlier under the cefuroxime example, resulted in cefazolin $\mathrm{CL}_{R}=0.0130 \mathrm{~L} / \mathrm{h} / \mathrm{kg}$ fetal weight. The combined fetal $\mathrm{CL}_{R}+\mathrm{CL}_{\text {intramembranous }}=0.0172 \mathrm{~L} / \mathrm{h} / \mathrm{kg}$ was incorporated into the model. Fetal tissue-to-plasma partition coefficients (Kps) were predicted within the Simulator using the Rodgers and Rowland method (Rodgers and Rowland, 2006) without any adjustment to the calculated tissue Kps. Performance of the developed model were verified against different clinical studies.

The following virtual trial designs were set for model building and prediction in pregnant subjects after the cefazolin administration:

Trial design P1: Single intravenous dose of $2000 \mathrm{mg}$ cefazolin infused over $10 \mathrm{~min}$ (van Hasselt et al., 2014); 20 trials of 20 pregnant women between $17-27$ GWs and aged $18-45$ years.

Trial design P2: Single intravenous dose of $2000 \mathrm{mg}$ cefazolin infused over $10 \mathrm{~min}$ (van Hasselt et al., 2014); 20 trials of 20 pregnant women between $28-34$ GWs and aged $18-45$ years.

Trial design P3: Single intravenous dose of $500 \mathrm{mg}$ cefazolin infused over $2 \mathrm{~min}$ (Philipson et al., 1987); 20 trials of 6 pregnant women between $19-33$ GWs and aged $22-57$ years.

Trial design P4: Single intravenous bolus dose of $2000 \mathrm{mg}$ cefazolin (Brown et al., 1990); 20 trials of 10 pregnant women between $23-32 \mathrm{GWs}$ and aged $18-45$ years.

Trial design P5: Single intravenous dose of $2000 \mathrm{mg}$ cefazolin infused over $30 \mathrm{~min} \mathrm{hr}$ (Allegaert et al., 2009); 20 trials of 49 pregnant women between 17 and 40 GWs and aged $18-45$ years. 
Trial design P6: Single intravenous bolus dose of 1000 mg cefazolin (Elkomy et al., 2014); 20 trials of 10 pregnant women at $39 \mathrm{GWs}$ and aged $23-43$ years.

Trial design P7: Single intravenous bolus dose of $1000 \mathrm{mg}$ cefazolin (Fiore Mitchell et al., 2001); 20 trials of 26 pregnant women between 37- 40 GWs and aged 22- 40 years.

Trial design P8: Single intravenous dose of $2000 \mathrm{mg}$ cefazolin infused over $7 \mathrm{~min}$ (Grupper et al., 2017); 20 trials of 32 pregnant women at $39 \mathrm{GWs}$ and aged $25-37$ years.

Trial design P9: Single intravenous bolus dose of either 2000 (or 3000) mg cefazolin (Kram et al., 2017); 20 trials of 65 pregnant women at 39 GWs and aged $27-32$ years. Conc reported at $1.833 \mathrm{hr}$ after dose administration

Trial design P10: Single intramuscular dose of $14 \mathrm{mg} / \mathrm{kg} \mathrm{mg}$ cefazolin (Bernard et al., 1977); 20 trials of 40 pregnant women between $15-20$ GWs and aged $18-45$ years.

\section{Amoxicillin}

Amoxicillin is semi-synthetic penicillin-derivative antibiotic with a broad spectrum of activity for treatment of several infections. It has a better absorption profile compared to cefuroxime and cefazolin and hence available as oral preparations. It has been reported that amoxycillin absorption displays apparent saturation kinetics (Westphal et al., 1991). Amoxicillin is mainly eliminated through the kidney and where OAT3 has been reported to be a key component of the drug secretion and its activity changes during pregnancy (Peng et al., 2021). 
Model building: A PBPK compound model for amoxicillin was built using published physicochemical properties and experimental data as well as predictive algorithms within the Simulator (See ESM Table S1 for the list of the model input). Model building and verifications results for non-pregnant subjects are also in the supplementary document. Amoxicillin undergoes hepatic biliary clearance (Maudgal et al., 1982) and this route of elimination was incorporated in the model (fitted using observed data (Dalhoff and Koeppe, 1982)). The elimination through the kidney was also incorporated in the model using the MechKim model. The MechKim model was parametrized using permeability clearance on both sides of the renal cells and active transporters at the proximal tubules using the basolateral OAT3 uptake transporter (Peng et al., 2021). Amoxicillin renal OAT3 clearance was optimized using the reported observed data (Dalhoff and Koeppe, 1982). The model then extended to oral route using first order absorption model. Parameter values for this model were fitted to recover observed plasma data after $500 \mathrm{mg}$ oral dose (Westphal et al., 1991). Predicted exposure in the non-pregnant and pregnant populations were compared to the observed data.

To extend the non-pregnant amoxicillin PBPK model to predict kinetics during pregnancy, the pregnancy population was used and the permeability-limited placenta model together with the full PBPK fetal model were selected. The fold change in the renal OAT3 transporter activity were included in the model as described in the cefazolin section. The obtained placental $C_{P D}$ clearance value of $0.0045 \mathrm{~L} / \mathrm{h} / \mathrm{mL}$ of placenta calculated from amoxicillin HBD and PSA. Fetal cefazolin renal clearance was calculated from amoxicillin renal clearance value in adult, as described earlier under the cefuroxime example, resulted in fetal amxicillin $C L_{R}=0.03985 \mathrm{~L} / \mathrm{h} / \mathrm{kg}$ fetal weight. The combined fetal $\mathrm{CL}_{R}+\mathrm{CL}_{\text {intramembranous }}(=0.044 \mathrm{~L} / \mathrm{h} / \mathrm{kg}$ fetal weight) were incorporated in the model before executing the simulations. All other 
fetal tissue-to-plasma partition coefficients (Kps) were predicted within the Simulator using the Rodgers and Rowland method (Rodgers and Rowland, 2006) without any adjustment to the calculated tissue Kps.

Predicted exposure in the pregnant populations were compared to the observed data. The following virtual trial designs were set for predicting amoxicillin pregnant subjects after maternal administration:

Trial design P1: Single 15-min infusion of 1g amoxicillin (Muller et al., 2008b); 20 trials of 34 pregnant women between $30-40 \mathrm{GWs}$ and aged $20-38$ years.

Trial design P2: Single 30-min infusion of 2g amoxicillin (Muller et al., 2008b); 20 trials of 34 pregnant women between $30-40 \mathrm{GWs}$ and aged $20-38$ years.

Trial design P3: A 30-min infusion of $2 \mathrm{~g}$ amoxicillin followed by 15 -min infusion of $1 \mathrm{~g}$ amoxicillin (5 hr apart) (Muller et al., 2008a); 20 trials of 17 pregnant women between 30 $37 \mathrm{GWs}$ and aged $20-35$ years.

Trial design P4: Single oral dose of 500 mg amoxicillin (Andrew et al., 2007); 20 trials of 16 pregnant women aged $20-37$ years at 18-22 GWs.

Trial design P5: Single oral dose of 500 mg amoxicillin (Andrew et al., 2007); 20 trials of 16 pregnant women aged $20-37$ years at 30-34 GWs.

Trial design P6: Single i.v. bolus of 1000mg amoxicillin (Zareba-Szczudlik et al., 2016); 20 trials of 35 pregnant women $38 \mathrm{GWs}$ and aged $20-40$ years.

Trial design P7: Single oral dose of 500mg amoxicillin (Zareba-Szczudlik et al., 2017); 20 trials of 30 pregnant women $38 \mathrm{GWs}$ and aged $22-42$ years. 


\section{Results}

\section{Cefuroxime}

PBPK predictions for cefuroxime in plasma of non-pregnant subjects after intravenous and intramuscular administration are shown in the supplementary materials (Fig. I). Predicted cefuroxime exposure during pregnancy are given in Fig. 2a for maternal systemic exposure, umbilical cord plasma level and for amniotic fluid. Pregnancy and fetal concentration predictions were obtained using fully bottom-up approach, i.e., without any parameter adjustment or fittings. Predicted exposure in different fetal organs are given in Fig. $2 \mathrm{~b}$. These results show adequate prediction of observed cefuroxime concentration profiles in non-pregnant and pregnant subjects as well as in the fetal organs. Comparison of the predicted PK parameters in non-pregnant subjects, and during pregnancy for the simulated trials with those available from clinical studies are given in Table 1. The differences between simulated and observed PK parameters were within 2-fold. Comparison of the predicted umbilical-to-maternal ratio of cefuroxime obtained from the simulated trials with those available from clinical studies are given in Table 2.

\section{Cefazolin}

Predicted systemic concentration profiles of cefazolin in plasma as well as derived PK parameters were generally in agreement with the observed data. Cefazolin PBPK model predictions for plasma level in non-pregnant women after intravenous and intramuscular administration are given in the supplementary materials (Fig. II). Predicted cefazolin 
concentration-time profiles in pregnancy compared to the clinical data are shown in Fig. 3a for maternal systemic exposure, umbilical vein, and amniotic fluid and in Fig. 3b for different fetal organs. These results were obtained via bottom-up approach for the feto-placental model without any parameter adjustment and agree with the observed data. The observed data are within the predicted $5^{\text {th }}-95^{\text {th }}$ percentiles range. Comparison of the predicted maternal cefazolin PK parameters obtained from the simulated trials with those available from clinical studies are given in Table 3. Comparison of the predicted cefazolin PK parameters obtained from the simulated trials with those available from clinical studies for the umbilical cord are given in Table 2 .

\section{Amoxicillin}

PBPK predictions for amoxycillin in plasma of non-pregnant subjects after intravenous and oral administration with overlayed data from 20 clinical studies are shown in the supplementary material (Fig. III). Comparison of the predicted vs observed amoxicillin PK parameters in nonpregnant subjects are shown in Table 4. These results show adequate model performance in non-pregnant population. Predicted amoxicillin exposure during pregnancy are given in Fig. 4 for maternal systemic exposure, umbilical cord plasma level and for amniotic fluid. Predictions were obtained without any parameter adjustment and gave adequate prediction of observed amoxicillin concentration profiles during different trimesters as well as at term. Comparison of the predicted PK parameters during pregnancy for the simulated trials with those available from clinical studies are given in Table 4 . The differences between simulated and observed PK parameters were within 2-fold. Limited data are available on amoxicillin exposure in the umbilical cord. Comparison of the 
predicted umbilical-to-maternal ratio of amoxicillin obtained from the simulated trials with those available from clinical studies are given in Table 2. 


\section{Discussion}

The current study utilizes the bottom-up population based PBPK approach to assess the performance of a fetal-maternal PBPK model within the Simcyp Simulator to predict maternal and fetal exposure without any fitting or adjustment to the physiological-related or compound-related parameters during pregnancy. Predicted parameters and profiles were compared against observed data taken from independent studies. The physiologically related PBPK model parameters that account for gestational age dependent physiology in the mother and the fetus together with the inter-individual variability (Abduljalil et al., 2012; Abduljalil et al., 2018; Abduljalil et al., 2019; Abduljalil et al., 2020a; Abduljalil et al., 2021) were also incorporated within the model to facilitate the prediction of drugs kinetics at different gestational weeks. The transplacental diffusions of these compounds were calculated using the physicochemical properties of the drug and integrated within the fetalmaternal PBPK model to determine fetal exposure.

The maternal renal clearance of cefuroxime and cefazolin was described using OAT3 and MRP4 transporters within the MechKiM model (Fig. 1). The maternal blood flow and GFR in this model are gestational age dependent according to previously published data (Abduljalil et al., 2012). For cefuroxime, the appropriateness of OAT3 was demonstrated by the in vivo observed $40 \%$ reduction on cefuroxime clearance by competitive inhibition with probenecid and the increased in cefuroxime AUC by $27 \%$ by co-administration of the OAT substrate NX059, while the contribution of MRP4 was estimated and its appropriateness was verified against the observed cumulative fraction of drug excreted unchanged in urine over 12 hours $\left(f e_{12 h}\right)$ (for more details see (Hsu et al., 2014)). Likewise, for cefazolin, the appropriateness of OAT3 contribution was verified against the observed $59 \%$ (vs $62 \%$ predicted) reduction in 
cefazolin clearance with probenecid (Brown et al., 1993). The predicted and observed profiles (supplementary material figure II) plot 11 for control and 12 with probenecid treatment are in good agreement. The appropriateness of MRP4 contribution was verified against the observed cumulative amount of cefazolin excreted unchanged in urine over 12 hours (see supplementary material Fig. IV). The predicted $f \mathrm{e}_{12 \mathrm{~h}}$ without MRP4 was $0.47 \pm 0.12$, while the predicted $f \mathrm{e}_{12 \mathrm{~h}}$ was $0.89 \pm 0.046$, which is within 1.19 -fold of the observed mean of $0.76 \pm 0.21$ (Rattie and Ravin, 1975), and 1.0-fold of observed value in single and multiple doses $0.89 \pm 0.30$ (Smyth et al., 1979).

Coupling the maternal cefuroxime PBPK model with the detailed fetoplacental compartments allowed prediction of cefuroxime disposition in the feto-placental model (Fig. 2a \& 2b). Cefuroxime PK parameters during pregnancy have not been adequately reported and are limited to those shown in Table 1 and 2. Cefuroxime clearance was reported to be 1.4 (predicted 1.2) and 1.3 (predicted 1.2)- fold higher during pregnancy (11 - 35 GWs) and at delivery than in non-pregnant women in the same subjects $(n=7)$, respectively (Philipson and Stiernstedt, 1982). This increase in cefuroxime clearance can be partly explained by the increase in the glomerulus filtration and/or increase in the activity of the involved OAT renal transporters. A recent work indicated that the activity of renal OAT1 at term is at nonpregnant capacity after being increased by 3 -fold during the second trimester (Peng et al., 2021). It is still unclear at what rate this transporter operate during the first trimester. While no informative data could be found to describe the changes in renal MRP4 transporter during pregnancy, the non-pregnant levels were assumed for these transporters to predict the drug kinetics during pregnancy in the current model. Since this cefuroxime PBPK model captured the pharmacokinetic in non-pregnant and pregnant populations adequately, including the observed increase in clearance during pregnancy, it seems that the impact of 
pregnancy on the activity of these transporters, at least for cefuroxime, is negligible (Fig. 2a and $2 b)$.

Calculated cefuroxime placental permeability using the physicochemical properties of the drug indicates rapid and significant permeation of the drug into the fetal circulation (i.e., $\left.C_{P D}=1.06 \mathrm{~L} / \mathrm{h}\right)$. This clearance resulted in adequate predictions of the observed placental, umbilical cord and fetal organs exposure (Takase et al., 1979; Bousfield et al., 1981; Craft et al., 1981; Philipson and Stiernstedt, 1982; Roumen et al., 1990; De Leeuw et al., 1993; Holt et al., 1993; Holt et al., 1994) (Fig. 2b \& 2c and Table 1 \& 2). Likewise, the calculated fetal renal, swallowing, and intramembranous clearances reflected the observed concentrations in the amniotic fluid (Fig. 2a \& 2b). The mean predicted cefuroxime cord/maternal plasma ratio was 0.8 (range: $0.6-1$ ), which agrees with observed concentration ratio of $0.83(0.42-$ 1.08) sampled within $9.5 \mathrm{~h}$ and $0.5(0.18-0.75)$ sampled within $4.5 \mathrm{~h}$ after drug administration (Craft et al., 1981) and $1.1(0.3-6)$ sampled within the first $5 \mathrm{~h}$ of drug administration (Philipson and Stiernstedt, 1982). Additional studies suggested a ratio of 1.5 (De Leeuw et al., 1993), and 0.45 (a mean of two groups of 0.6 and 0.3) (Holt et al., 1994).

The cefazolin PBPK predictions show good agreement with the observed data in nonpregnant and pregnant subjects. The developed model predicts an increasing cefazolin maternal clearance during pregnancy. The predicted systemic clearance increases by $70 \%$ of non-pregnant value at $20 \mathrm{GWs}$ and gradually decreases to approximately $60 \%$ at term, which agrees with observed increases of 57\% (Philipson et al., 1987) and 74\% (Elkomy et al., 2014) in cefazolin clearance during pregnancy compared with postpartum values. The activity of renal OAT3 during pregnancy was incorporated as a continuous function to allow 
scaling the activity of this transporter at each gestational week. Calculated cefazolin placental permeability using the physicochemical properties of the drug resulted in a diffusion clearance of approximately $1 \mathrm{~L} / \mathrm{h}$, which indicates rapid and significant permeation of the drug into the fetal circulation. The predicted umbilical exposure at delivery described the observed exposure adequately (Fig. 3a). The predicted umbilical vein exposure is about $50 \%$ of the maternal plasma.

The observed changes in amoxicillin exposure during different trimesters were well captured using the developed gestational age dependent renal OAT3 function. This case supports the adequacy of fold-change in the activity of this transporter when applied to describe the disposition of cefazolin during pregnancy. Based on the limited observed amoxicillin concentration at $2 \mathrm{~h}$ (Zareba-Szczudlik et al., 2016; Zareba-Szczudlik et al., 2017), the model predicted maternal, placenta and amniotic exposure, adequately, but overpredicted the umbilical concentration (Fig. 4). Based on these results, the usefulness of the used physicochemical properties, i.e., HBD and PSA, to predict the umbilical exposure is still unconclusive.

Ratios of predicted cord-maternal ratio against observed ratios from different studies are shown in Table 2. The umbilical cord and amniotic fluid drug concentration profiles in general does not change in parallel to the drug profile in the maternal circulation, even if placental transporters are not involved, especially after single dose administration. This can be very prominent after single intravenous dose where, shortly after administration, the maternal concentration is at its maximum level, but the umbilical concentration is almost zero. Quantification of the cord/maternal or amniotic/maternal ratios at specific time point will result in time-dependent cord/maternal ratio and make it difficult to compare ratios 
from different studies using different time points. For example, if the reported cord and maternal cefazolin concentrations in Fiore et al., (Fiore Mitchell et al., 2001) were used to calculate the cord-maternal ratio during the first hour after drug administration, a mean value of 0.2 is obtained, which is less than the ratio of $0.52-0.62$ reported by other studies (Elkomy et al., 2014; Kram et al., 2017). If the ratio is calculated from reported concentrations between 1.5 and $7 \mathrm{~h}$, when the umbilical cord concentration rises, a mean value of 0.6 was obtained, which agrees with other clinical studies as well as with the predicted ratio. A very low ratio of 0.16 was reported from 7 pregnancies (Brown et al., 1990), owing primarily to the short sampling times of less than $1 \mathrm{~h}$.

Large variability in the clinical data have been observed, especially for the amniotic exposure even after administration of comparable doses. Due to the nature of the conducted clinical studies, many of them reported lumped results from wider gestational age range, that stretches over two trimesters (Philipson and Stiernstedt, 1982; Holt et al., 1993; Allegaert et al., 2009), limited in sample size (Philipson and Stiernstedt, 1982; Brown et al., 1990) and/or lumped data were reported from pregnant women received different doses (Bousfield et al., 1981; van Hasselt et al., 2014). It should however be pointed out that the placental permeability results in the current study are predicted using equation that was built to predict permeability through intestinal membrane from HBD counts and PSA of the relatively small compounds (Yang et al., 2007). Therefore, it is unlikely to be predictive for larger molecules with more HBD counts and/or where specific placental transports are involved as in case of vancomycin, amikacin, or gentamicin (Akour et al., 2015).

The obtained permeability from this function is in length/time unit and the placental surface area was used to scale this value to volume/time/placenta to represent placental 
permeability clearance. While the predicted transplacental diffusion verified with available maternal, umbilical, amniotic and placental data at term (Fig. 2a, 3a and 4), the availability of cefuroxime (Takase et al., 1979) and cefazolin (Bernard et al., 1977) data from different fetal organs allowed us to challenge the implemented model to simultaneously assess the integrity of dynamic physiology and drug properties for predicting fetal cefuroxime exposureat term (Fig. 2b) as well as cefazolin exposure at the end of first trimester (Fig. 3b) without any parameter adjustment. The obtained adequate predictions of umbilical and fetal organ exposure in both cases reenforces the utility of the proposed models. Since data on placental transporter kinetics are still not available for all compounds investigated in the current work, their transplacental passages were described assuming passive permeability.

The extra-membranous drug flow into and from the amniotic fluid was set to zero in this study as this clearance pathway and how it is affected by underlying disease conditions is poorly understood. This limitation may contribute to the underprediction of early amniotic exposure observed in few studies.

\section{Conclusion}

The detailed maternal-fetal PBPK model developed in this work successfully predicted the drug kinetics during pregnancy of cefuroxime, cefazolin, and amoxicillin. The model provided insight into the exposure within different fetal organs supported by limited observations. This was facilitated parametrizing the diffusion clearance through the bloodplacenta barrier scaled up from physicochemical properties of the drugs without any refinement of the model parameters. There is a need for more work in this area to characterize the drug transfer from and into the amniotic fluid of those antibiotics. The 
development of a pregnancy PBPK model is a promising approach to predict not only maternal and umbilical, but fetal tissue exposure at different stages of pregnancy. This study demonstrates the utility of the pregnancy PBPK modelling as a generic tool for predicting maternal and fetal kinetics of renally excreted drugs and can be used for assessing dose adjustment. The fetal PBPK model should be viewed as a "live" model which undergoes continuous enhancements as knowledge of mechanisms of drug distribution and elimination within the fetoplacental unit increases. While the level of confidence in these models at any given time reflects the state of existing knowledge and the capability to incorporate such knowledge, they can play an important role in understanding of drugs safety and efficacy for both the mother and the developing fetus. The developed PBPK models provides an important and promising approach in the optimal design of clinical PK studies to predict maternal and fetal drug exposure at different stages of pregnancy. 


\section{Acknowledgments}

We thank Eleanor Savill and Anna Kenworthy for their assistance with collecting the references and preparing the manuscript.

\section{Author contribution:}

Participated in research design: KA

Conducted experiments: KA, JN, AP, XP

Performed Data Analysis: KA, JN, AP, XP

Wrote or contributed to the writing of the manuscript: KA, MJ, JN, AP, XP 


\section{References}

Abduljalil K and Badhan RKS (2020) Drug dosing during pregnancy-opportunities for physiologically based pharmacokinetic models. J Pharmacokinet Pharmacodyn 47:319-340.

Abduljalil K, Furness P, Johnson TN, Rostami-Hodjegan A, and Soltani H (2012) Anatomical, physiological and metabolic changes with gestational age during normal pregnancy: a database for parameters required in physiologically based pharmacokinetic modelling. Clin Pharmacokinet 51:365-396.

Abduljalil K, Jamei M, and Johnson TN (2019) Fetal Physiologically Based Pharmacokinetic Models: Systems Information on the Growth and Composition of Fetal Organs. Clin Pharmacokinet 58:235-262.

Abduljalil K, Jamei M, and Johnson TN (2020a) Fetal Physiologically Based Pharmacokinetic Models: Systems Information on Fetal Blood Components and Binding Proteins. Clin Pharmacokinet 59:629-642.

Abduljalil K, Johnson TN, and Rostami-Hodjegan A (2018) Fetal Physiologically-Based Pharmacokinetic Models: Systems Information on Fetal Biometry and Gross Composition. Clin Pharmacokinet 57:1149-1171.

Abduljalil K, Pan X, Clayton R, Johnson TN, and Jamei M (2021) Fetal Physiologically Based Pharmacokinetic Models: Systems Information on Fetal Cardiac Output and Its Distribution to Different Organs during Development. Clin Pharmacokinet 60:741757. 
Abduljalil K, Pan X, Pansari A, Jamei M, and Johnson TN (2020b) A Preterm Physiologically Based Pharmacokinetic Model. Part I: Physiological Parameters and Model Building. Clin Pharmacokinet 59:485-500.

Abduljalil K, Pansari A, and Jamei M (2020c) Prediction of maternal pharmacokinetics using physiologically based pharmacokinetic models: assessing the impact of the longitudinal changes in the activity of CYP1A2, CYP2D6 and CYP3A4 enzymes during pregnancy. J Pharmacokinet Pharmacodyn 47:361-383.

Adam D, Koeppe P, and Heilmann HD (1983) Pharmacokinetics of amoxicillin and flucloxacillin following the simultaneous intravenous administration of $4 \mathrm{~g}$ and $1 \mathrm{~g}$, respectively. Infection 11:150-154.

Akour AA, Kennedy MJ, and Gerk PM (2015) The Role of Megalin in the Transport of Gentamicin Across BeWo Cells, an In Vitro Model of the Human Placenta. AAPS J 17:1193-1199.

Allegaert K, van Mieghem T, Verbesselt R, de Hoon J, Rayyan M, Devlieger R, Deprest J, and Anderson BJ (2009) Cefazolin pharmacokinetics in maternal plasma and amniotic fluid during pregnancy. Am J Obstet Gynecol 200:170 e171-177.

Alrammaal HH, Batchelor HK, Morris RK, and Chong HP (2019) Efficacy of perioperative cefuroxime as a prophylactic antibiotic in women requiring caesarean section: A systematic review. Eur J Obstet Gynecol Reprod Biol 242:71-78.

Andrew MA, Easterling TR, Carr DB, Shen D, Buchanan ML, Rutherford T, Bennett R, Vicini P, and Hebert MF (2007) Amoxicillin pharmacokinetics in pregnant women: modeling and simulations of dosage strategies. Clin Pharmacol Ther 81:547-556. 
Arancibia A, Guttmann J, Gonzalez G, and Gonzalez C (1980) Absorption and disposition kinetics of amoxicillin in normal human subjects. Antimicrob Agents Chemother 17:199-202.

Bernard B, Barton L, Abate M, and Ballard CA (1977) Maternal-fetal transfer of cefazolin in the first twenty weeks of pregnancy. J Infect Dis 136:377-382.

Blackburn S (2007) Maternal, fetal and neonatal physiology: a clinical perspective. Saunders Elsevier, Philadelphia.

Bookstaver PB, Bland CM, Griffin B, Stover KR, Eiland LS, and McLaughlin M (2015) A Review of Antibiotic Use in Pregnancy. Pharmacotherapy 35:1052-1062.

Bouazza N, Foissac F, Hirt D, Urien S, Benaboud S, Lui G, and Treluyer JM (2019) Methodological Approaches to Evaluate Fetal Drug Exposure. Curr Pharm Des 25:496-504.

Bousfield P, Browning AK, Mullinger BM, and Elstein M (1981) Cefuroxime: potential use in pregnant women at term. Br J Obstet Gynaecol 88:146-149.

Boyd PA (1984) Quantitative structure of the normal human placenta from 10 weeks of gestation to term. Early Hum Dev 9:297-307.

Brown CE, Christmas JT, and Bawdon RE (1990) Placental transfer of cefazolin and piperacillin in pregnancies remote from term complicated by Rh isoimmunization. Am J Obstet Gynecol 163:938-943.

Brown G, Zemcov SJ, and Clarke AM (1993) Effect of probenecid on cefazolin serum concentrations. J Antimicrob Chemother 31:1009-1011.

Ci L, Kusuhara H, Adachi M, Schuetz JD, Takeuchi K, and Sugiyama Y (2007) Involvement of MRP4 (ABCC4) in the luminal efflux of ceftizoxime and cefazolin in the kidney. Molecular pharmacology 71:1591-1597. 
Craft I, Mullinger BM, and Kennedy MR (1981) Placental transfer of cefuroxime. Br J Obstet Gynaecol 88:141-145.

Dalhoff A and Koeppe P (1982) Comparative pharmacokinetic analysis of amoxycillin using open two and three-compartment models. Eur J Clin Pharmacol 22:273-279.

De Leeuw JW, Roumen FJ, Bouckaert PX, Cremers HM, and Vree TB (1993) Achievement of therapeutic concentrations of cefuroxime in early preterm gestations with premature rupture of the membranes. Obstet Gynecol 81:255-260.

De Sousa Mendes M, Lui G, Zheng Y, Pressiat C, Hirt D, Valade E, Bouazza N, Foissac F, Blanche S, Treluyer JM, Urien S, and Benaboud S (2017) A Physiologically-Based Pharmacokinetic Model to Predict Human Fetal Exposure for a Drug Metabolized by Several CYP450 Pathways. Clin Pharmacokinet 56:537-550.

Elkomy MH, Sultan P, Drover DR, Epshtein E, Galinkin JL, and Carvalho B (2014)

Pharmacokinetics of prophylactic cefazolin in parturients undergoing cesarean delivery. Antimicrob Agents Chemother 58:3504-3513.

Fiore Mitchell T, Pearlman MD, Chapman RL, Bhatt-Mehta V, and Faix RG (2001) Maternal and transplacental pharmacokinetics of cefazolin. Obstet Gynecol 98:1075-1079. Foord RD (1976) Cefuroxime: human pharmacokinetics. Antimicrob Agents Chemother 9:741-747.

Garton AM, Rennie RP, Gilpin J, Marrelli M, and Shafran SD (1997) Comparison of dose doubling with probenecid for sustaining serum cefuroxime levels. J Antimicrob Chemother 40:903-906.

Gower PE and Dash CH (1977) The pharmacokinetics of cefuroxime after intravenous injection. Eur J Clin Pharmacol 12:221-227. 
Grupper M, Kuti JL, Swank ML, Maggio L, Hughes BL, and Nicolau DP (2017) Population Pharmacokinetics of Cefazolin in Serum and Adipose Tissue From Overweight and Obese Women Undergoing Cesarean Delivery. J Clin Pharmacol 57:712-719.

Harding SM, Eilon LA, and Harris AM (1979) Factors affecting the intramuscular absorption of cefuroxime. J Antimicrob Chemother 5:87-93.

Hill SA, Jones KH, and Lees $\amalg$ (1980) Pharmacokinetics of parenterally administered amoxycillin. J Infect 2:320-332.

Holt DE, Broadbent M, Spencer JA, de Louvois J, Hurley R, and Harvey D (1994) The placental transfer of cefuroxime at parturition. Eur J Obstet Gynecol Reprod Biol 54:177-180.

Holt DE, Fisk NM, Spencer JA, de Louvois J, Hurley R, and Harvey D (1993) Transplacental transfer of cefuroxime in uncomplicated pregnancies and those complicated by hydrops or changes in amniotic fluid volume. Arch Dis Child 68:54-57.

Hsu V, de LTVM, Zhao P, Zhang L, Zheng JH, Nordmark A, Berglund EG, Giacomini KM, and Huang SM (2014) Towards quantitation of the effects of renal impairment and probenecid inhibition on kidney uptake and efflux transporters, using physiologically based pharmacokinetic modelling and simulations. Clin Pharmacokinet 53:283-293.

Hvidberg H, Struve C, Krogfelt KA, Christensen N, Rasmussen SN, and Frimodt-Moller N (2000) Development of a long-term ascending urinary tract infection mouse model for antibiotic treatment studies. Antimicrob Agents Chemother 44:156-163.

Kagedal M, Nilsson D, Huledal G, Reinholdsson I, Cheng YF, Asenblad N, Pekar D, and Borga O (2007) A study of organic acid transporter mediated pharmacokinetic interaction between NXY-059 and cefuroxime. J Clin Pharmacol 47:1043-1048.

Kirby WM and Regamey C (1973) Pharmacokinetics of cefazolin compared with four other cephalosporins. J Infect Dis 128:Suppl:S341-346. 
Kram JJF, Greer DM, Cabrera O, Burlage R, Forgie MM, and Siddiqui DS (2017) Does current cefazolin dosing achieve adequate tissue and blood concentrations in obese women undergoing cesarean section? Eur J Obstet Gynecol Reprod Biol 210:334-341.

Lalic-Popovic M, Paunkovic J, Grujic Z, Golocorbin-Kon S, Milasinovic L, Al-Salami H, and Mikov M (2016) Decreased placental and transcellular permeation of cefuroxime in pregnant women with diabetes. J Diabetes 8:238-245.

Lee SM, Park SK, Shim SS, Jun JK, Park JS, and Syn HC (2007) Measurement of fetal urine production by three-dimensional ultrasonography in normal pregnancy. Ultrasound Obstet Gynecol 30:281-286.

Maged AM, Abdelmoneim A, Said W, and Mostafa WA (2014) Measuring the rate of fetal urine production using three-dimensional ultrasound during normal pregnancy and pregnancy-associated diabetes. J Matern Fetal Neonatal Med 27:1790-1794.

Mathialagan S, Piotrowski MA, Tess DA, Feng B, Litchfiled J, and Varma MV (2017) Quantitative prediction of human renal clearance and drug-drug interactions of organic anion transporter substrates using in vitro transport data. Drug Metab Dispos 45:409-417.

Maudgal DP, Maxwell JD, Lees LJ, and Wild RN (1982) Biliary excretion of amoxycillin and ceftriaxone after intravenous administration in man. Br J Clin Pharmacol 14:213-217. Mayhew TM (2001) Fibrin-type fibrinoid in human placenta: a stereological analysis of its association with intervillous volume and villous surface area. Image Anal Stereol 20:1-7.

Muanda FT, Sheehy O, and Berard A (2017) Use of antibiotics during pregnancy and the risk of major congenital malformations: a population based cohort study. Br J Clin Pharmacol 83:2557-2571. 
Muller AE, DeJongh J, Oostvogel PM, Voskuyl RA, Dorr PJ, Danhof M, and Mouton JW (2008a) Amoxicillin pharmacokinetics in pregnant women with preterm premature rupture of the membranes. Am J Obstet Gynecol 198:108 e101-106.

Muller AE, Dorr PJ, Mouton JW, De Jongh J, Oostvogel PM, Steegers EA, Voskuyl RA, and Danhof M (2008b) The influence of labour on the pharmacokinetics of intravenously administered amoxicillin in pregnant women. Br J Clin Pharmacol 66:866-874.

Neuhoff S, Gaohua L, Burt H, Jamei M, Li L, Tucker GT, and Rostami-Hodjegan A (2013) Accounting for Transporters in Renal Clearance: Towards a Mechanistic Kidney Model (Mech KiM), in: Transporters in Drug Development AAPS Advances in the Pharmaceutical Sciences Series (Sugiyama Y and Steffansen B eds), Springer, New York, NY.

O'Callaghan CH and Harding SM (1977) The Pharmacokinetics of Cefuroxime in Man in Relation to its Antibacterial Activity. . Proc R Soc Med 70 (Suppl 9):4-10.

Pacifici GM (2006) Placental transfer of antibiotics administered to the mother: a review. Int J Clin Pharmacol Ther 44:57-63.

Peng J, Ladumor MK, and Unadkat JD (2021) Prediction of pregnancy-induced changes in secretory and total renal clearance of drugs transported by organic anion transporters. Drug Metab Dispos 49:929-937.

Philipson A and Stiernstedt G (1982) Pharmacokinetics of cefuroxime in pregnancy. Am J Obstet Gynecol 142:823-828.

Philipson A, Stiernstedt G, and Ehrnebo M (1987) Comparison of the pharmacokinetics of cephradine and cefazolin in pregnant and non-pregnant women. Clin Pharmacokinet 12:136-144. 
Pires de Abreu LR, Ortiz RM, de Castro SC, and Pedrazzoli J, Jr. (2003) HPLC determination of amoxicillin comparative bioavailability in healthy volunteers after a single dose administration. J Pharm Pharm Sci 6:223-230.

Prevot MH, Jehl F, and Rouveix B (1997) Pharmacokinetics of a new oral formulation of amoxicillin. Eur J Drug Metab Pharmacokinet 22:47-52.

Rattie ES and Ravin LJ (1975) Pharmacokinetic interpretation of blood levels and urinary excretion data for cefazolin and cephalothin after intravenous and intramuscular administration in humans. Antimicrob Agents Chemother 7:606-613.

Rayburn WF and Farmer KC (1997) Off-label prescribing during pregnancy. Obstet Gynecol Clin North Am 24:471-478.

Rhodin MM, Anderson BJ, Peters AM, Coulthard MG, Wilkins B, Cole M, Chatelut E, Grubb A, Veal GJ, Keir MJ, and Holford NH (2009) Human renal function maturation: a quantitative description using weight and postmenstrual age. Pediatr Nephrol 24:6776.

Rodgers T and Rowland M (2006) Physiologically based pharmacokinetic modelling 2: predicting the tissue distribution of acids, very weak bases, neutrals and zwitterions. J Pharm Sci 95:1238-1257.

Roumen FJ, Bouckaert PX, Cremers HM, and Vree TB (1990) Pharmacokinetics of cefuroxime in pregnant patients with preterm premature rupture of the membranes. Pharm Weekbl Sci 12:275-279.

Schalkwijk S, Buaben AO, Freriksen JJM, Colbers AP, Burger DM, Greupink R, and Russel FGM (2018) Prediction of Fetal Darunavir Exposure by Integrating Human Ex-Vivo Placental Transfer and Physiologically Based Pharmacokinetic Modeling. Clin Pharmacokinet 57:705-716. 
Scheld WM, Spyker DA, Donowitz GR, Bolton WK, and Sande MA (1981) Moxalactam and cefazolin: comparative pharmacokinetics in normal subjects. Antimicrob Agents Chemother 19:613-619.

Schmidt A, Morales-Prieto DM, Pastuschek J, Frohlich K, and Markert UR (2015) Only humans have human placentas: molecular differences between mice and humans. $J$ Reprod Immunol 108:65-71.

Smyth RD, Pfeffer M, Glick A, Van Harken DR, and Hottendorf GH (1979) Clinical pharmacokinetics and safety of high doses of ceforanide (BL-S786R) and cefazolin. Antimicrob Agents Chemother 16:615-621.

Takase Z, Shirofuji H, and Uchida M (1979) Fundamental and clinical studies of cefuroxime in the field of obstetrics and gynecology. Chemotherapy 27:600-602.

Teasdale F and Jean-Jacques G (1985) Morphometric evaluation of the microvillous surface enlargement factor in the human placenta from mid-gestation to term. Placenta 6:375-381.

Thonnings S, Jensen KS, Nielsen NB, Skjonnemand M, Hansen DS, Lange KHW, and FrimodtMoller N (2020) Cefuroxime pharmacokinetics and pharmacodynamics for intravenous dosage regimens with $750 \mathrm{mg}$ or $1500 \mathrm{mg}$ doses in healthy young volunteers. J Med Microbiol 69:387-395.

Touboul C, Boulvain M, Picone O, Levaillant JM, Frydman R, and Senat MV (2008) Normal fetal urine production rate estimated with 3-dimensional ultrasonography using the rotational technique (virtual organ computer-aided analysis). Am J Obstet Gynecol 199:57 e51-55.

Underwood MA, Gilbert WM, and Sherman MP (2005) Amniotic fluid: not just fetal urine anymore. J Perinatol 25:341-348. 
van Dalen R, Vree TB, Hafkenscheid JC, and Gimbrere JS (1979) Determination of plasma and renal clearance of cefuroxime and its pharmacokinetics in renal insufficiency. $J$ Antimicrob Chemother 5:281-292.

van Hasselt JG, Allegaert K, van Calsteren K, Beijnen JH, Schellens JH, and Huitema AD (2014) Semiphysiological versus empirical modelling of the population pharmacokinetics of free and total cefazolin during pregnancy. Biomed Res Int 2014:897216.

Verhagen CA, Mattie H, and Van Strijen E (1994) The renal clearance of cefuroxime and ceftazidime and the effect of probenecid on their tubular excretion. $\mathrm{Br} J \mathrm{Clin}$ Pharmacol 37:193-197.

Viel-Theriault I, Fell DB, Grynspan D, Redpath S, and Thampi N (2019) The transplacental passage of commonly used intrapartum antibiotics and its impact on the newborn management: A narrative review. Early Hum Dev 135:6-10.

Westphal JF, Deslandes A, Brogard JM, and Carbon C (1991) Reappraisal of amoxycillin absorption kinetics. J Antimicrob Chemother 27:647-654.

Yang J, Jamei M, Yeo KR, Tucker GT, and Rostami-Hodjegan A (2007) Prediction of intestinal first-pass drug metabolism. Curr Drug Metab 8:676-684.

Zareba-Szczudlik J, Romejko-Wolniewicz E, Lewandowski Z, Rozanska H, MalinowskaPolubiec A, Dobrowolska-Redo A, Wilczynski J, and Czajkowski K (2016) Evaluation of the amoxicillin concentrations in amniotic fluid, placenta, umbilical cord blood and maternal serum two hours after intravenous administration. Neuro Endocrinol Lett 37:403-409.

Zareba-Szczudlik J, Romejko-Wolniewicz E, Lewandowski Z, Rozanska H, MalinowskaPolubiec A, Dobrowolska-Redo A, Wilczynski J, and Czajkowski K (2017) Evaluation of the amoxicillin concentrations in amniotic fluid, placenta, umbilical cord blood and 
maternal serum two hours after oral administration. Neuro Endocrinol Lett 38:502508.

Zarowny D, Ogilvie R, Tamblyn D, MacLeod C, and Ruedy J (1974) Pharmacokinetics of amoxicillin. Clin Pharmacol Ther 16:1045-1051.

Zhang Z, Imperial MZ, Patilea-Vrana GI, Wedagedera J, Gaohua L, and Unadkat JD (2017) Development of a Novel Maternal-Fetal Physiologically Based Pharmacokinetic Model I: Insights into Factors that Determine Fetal Drug Exposure through Simulations and Sensitivity Analyses. Drug Metab Dispos 45:920-938.

Zhang Z and Unadkat JD (2017) Development of a Novel Maternal-Fetal Physiologically Based Pharmacokinetic Model II: Verification of the model for passive placental permeability drugs. Drug Metab Dispos 45:939-946.

\section{Figure Legends}

Fig.1 Structure of the full Maternal-Placental-Fetal Model within the Simcyp Simulator V20 coupled with the MechKiM model. Note: For MechKiM model: both renal blood flow and GFR are gestational age dependent, hence the flows between kidney compartments are gestational age dependent (Solid black arrows). Broken arrows represent directions of efflux and uptake transporters 
Fig. 2a. PBPK predicted (lines) vs observed (circles) cefuroxime concentration profiles in pregnant women after intravenous (Plots A to $\mathrm{G} 2$ ) and intramuscular (Plots $\mathrm{H} 1-\mathrm{H} 4$ ) doses. Plot A: $750 \mathrm{mg}$ over $1 \mathrm{~min}$ at 11-35 GWs (Philipson and Stiernstedt, 1982), Plots B1 \& B3: $750 \mathrm{mg}$ over $1 \mathrm{~min}$ at 37-42 GWs (Philipson and Stiernstedt, 1982), Plots C1 \& C2: $750 \mathrm{mg}$ over 3 min 35-40 GWs (Holt et al., 1994), Plots D1 \& D2: 1500 mg over 3 min 38-40 GWs (Holt et al., 1994), Plot E: 750 mg over 3 min 38-40 GWs (Holt et al., 1993), Plot F: 1500 mg over $1 \mathrm{~min}$ at term (Bousfield et al., 1981), Plots G1 \& G2: two A dose of 1500 mg over 1 min at term repeated after 4hr (Bousfield et al., 1981) of cefuroxime, Plots H1 - H4: 750 mg i.m. at term (Craft et al., 1981) and Plots I1 - I 14: 1500 mg i.v. every 8 hours (Roumen et al., 1990; De Leeuw et al., 1993) with filled circles in I1 \& I2 from Roumen et al., (Roumen et al., 1990), while horizontal lines in 13 represent min, geomean and max values from 9 placental homogenate samples (sampling times were not available), error bar represent standard deviation and profiles in 14 represent reported min, median and max values from 81 amniotic fluid samples (De Leeuw et al., 1993). Observed concentration are shown as open circles (Maternal), orange circles (umbilical vein plasma) and blue circles (amniotic fluid). Bold continuous lines are the predicted means. Broken lines are the $5^{\text {th }}$ and $95^{\text {th }}$ percentiles. See "Methods" section for trial settings.

Fig. 2b. PBPK predicted vs observed (circles) maternal, placental, amniotic, and fetal cefuroxime concentration after administration of single IV bolus of $750 \mathrm{mg}$ of cefuroxime (Takase et al., 1979) to pregnant women at term (40 GW). Bold continuous lines are the predicted means. Broken lines are the $5^{\text {th }}$ and $95^{\text {th }}$ percentiles. See "Methods" section for trial settings. 
Fig. 3a PBPK predicted vs observed (circles) cefazolin concentration profiles in pregnant women after single intravenous doses. Plot A1 \& A2: 17-28 GWs (van Hasselt et al., 2014), Plot B1 \& B2: 28-40 GWs (van Hasselt et al., 2014), Plot C: 19-33 GWs (Bernard et al., 1977), Plot D: 23-32 GWs (Brown et al., 1990), Plot E: 17-40 GWs (Allegaert et al., 2009), Plot F: 39 GWs (Elkomy et al., 2014), Plot G: 37-40GWs (Fiore Mitchell et al., 2001), Plot H: 39 GWs (Grupper et al., 2017). Plot I and J are for Predicted (diamonds) vs observed cefazolin concentrations at $1.83 \mathrm{hr}$ in maternal and umbilical at $39 \mathrm{GWs}$ in overweight and obese pregnant women (Kram et al., 2017). Observed concentration are shown as open circles (Maternal), red circles (umbilical vein plasma), green circles (amniotic fluid) and orange circles (placental tissue). Bold continuous lines are the predicted means, and the broken lines are the $5^{\text {th }}$ and $95^{\text {th }}$ percentiles. See "Methods" section for trial settings.

Fig. 3b. PBPK predicted vs observed (circles) maternal, placental, amniotic, and fetal cefazolin concentration after administration of single intramuscular dose of $14 \mathrm{mg} / \mathrm{kg}$ cefazolin (Bernard et al., 1977) to pregnant women between $15-20$ GWs. Observed concentration are shown as open circles (Maternal), redcircles (umbilical vein plasma),green circles (amniotic fluid) and orange circles (placental tissue). Bold continuous lines are the predicted means, and the broken lines are the $5^{\text {th }}$ and $95^{\text {th }}$ percentiles. See "Methods" section for trial settings. Horizontal lines represent the least detectable values measured during the sampling window as the exact sampling time was unknown; horizontal solid line in the fetal brain plot represents the measured CSF value. 
Fig. 4 PBPK predicted vs observed (circles) amoxicillin concentration profiles in pregnant women after intravenous and oral administrations. Predictions after pre-delivery infusion doses of $1 \mathrm{~g}$ (Plot A (Muller et al., 2008b)) and 2g (Plot B (Muller et al., 2008b)) amoxycillin (red circles= at labour, open circles=pre-labour) and two consequent infusions of $2 \mathrm{~g}$ and $1 \mathrm{~g}$ of amoxicillin pre-labour (Plot C (Muller et al., 2008a)). Oral doses of 500mg in non-pregnant (Plot D (Andrew et al., 2007)), during $2^{\text {nd }}$ trimester (Plot E (Andrew et al., 2007)) and $3^{\text {rd }}$ trimester (Plot F (Andrew et al., 2007)). Reported minimum, mean, and maximum measured amoxicillin concentration in different feto-maternal tissues after maternal amoxicillin administration of $1000 \mathrm{mg}$ intravenously (Plot G1 to G4 (Zareba-Szczudlik et al., 2016)) and orally (Plot H1 to H4 (Zareba-Szczudlik et al., 2017)) at term. Bold continuous lines are the predicted means, and the broken lines are the $5^{\text {th }}$ and $95^{\text {th }}$ percentiles. See "Methods" section for trial settings. 
Table 1: Predicted vs observed PK parameters of cefuroxime in non-pregnant subjects and during pregnancy after:

\begin{tabular}{|c|c|c|c|c|c|c|c|c|c|c|c|}
\hline & \multirow{2}{*}{ Study design; Population n (\%F) } & \multirow{2}{*}{ GWs } & \multicolumn{3}{|c|}{$\mathrm{CL}(\mathrm{L} / \mathrm{h})$} & \multicolumn{3}{|c|}{ AUC (mg. h/L) } & \multicolumn{3}{|c|}{ Half-life $(\mathrm{h})$} \\
\hline & & & Obs & Pred & Ratio & Obs & Pred & Rat范 & Obs & Pred & Ratio \\
\hline \multirow{17}{*}{ 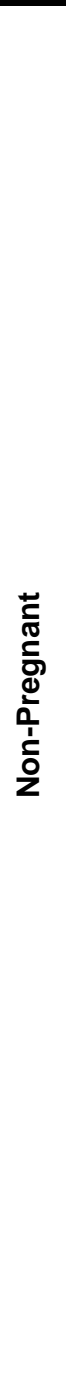 } & $\begin{array}{l}\text { Single } 0.75 \mathrm{~g} \text { i.v. infusion ; } 10 \\
(50 \%) \text { (Garton et al., 1997) }\end{array}$ & NA & 10.0 & $11.0(3.2)$ & 1.13 & $77.0(10)$ & $73.0(22)$ & $0.9 \frac{0}{0}$ & NA & $0.86(0.24)$ & NA \\
\hline & $\begin{array}{l}\text { Single } 1.5 \mathrm{~g} \text { i.v. infusion ; } 10 \text { (50\%) } \\
\text { (Garton et al., 1997) }\end{array}$ & NA & 11.0 & $11.0(3.2)$ & 1.00 & $137(20)$ & $147(44)$ & 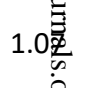 & NA & $0.86(0.24)$ & NA \\
\hline & $\begin{array}{l}\text { Single } 0.667 \text { g i.v. bolus ; } 20 \\
(50 \%)(\text { Thonnings et al., } 2020)\end{array}$ & NA & $16.0(2.1)$ & $11.0(3.1)$ & 0.69 & 41.7 & $67.0(19)$ & 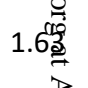 & NA & $0.90(0.25)$ & NA \\
\hline & $\begin{array}{l}\text { Single } 1.375 \text { g i.v. bolus; } 20 \\
(50 \%)(\text { Thonnings et al., } 2020 \text { ) }\end{array}$ & NA & $16.0(2.1)$ & $11.0(3.1)$ & 0.69 & 85.9 & $137(39)$ & 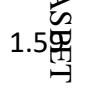 & NA & $0.90(0.25)$ & NA \\
\hline & $\begin{array}{l}\text { Single } 0.5 \mathrm{~g} \text { i.v. bolus; } 6(0 \%) \text { (Gower } \\
\text { and Dash, 1977) }\end{array}$ & NA & $9.4(2.5)$ & $11.1(3.3)$ & 1.18 & $53.1(18.1)$ & $49.3(15)$ & 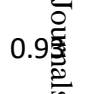 & $1.14(0.26)$ & $0.95(0.24)$ & 0.83 \\
\hline & $\begin{array}{l}\text { Single } 0.75 \mathrm{~g} \text { i.v. bolus; } 6 \text { (0\%)(Gower } \\
\text { and Dash, 1977) }\end{array}$ & NA & $10.1(1.5)$ & $11.1(3.3)$ & 1.10 & $74.0(13.8)$ & $73.9(22.4)$ & $\stackrel{1.08}{\perp}$ & $1.10(0.27)$ & $0.95(0.24)$ & 0.86 \\
\hline & $\begin{array}{l}\text { Single } 0.25 \text { g i.v. bolus; } 3 \text { (0\%)(Foord, } \\
\text { 1976) }\end{array}$ & NA & 7.67 & $11.6(3.4)$ & 1.51 & $32.6(1.1)$ & $23.6(7.6)$ & $0.7 \sqrt[2]{2}$ & $1.0(0.2)$ & $0.91(0.26)$ & 0.91 \\
\hline & $\begin{array}{l}\text { Single } 0.5 \mathrm{~g} \text { i.v. bolus; } 3 \text { (0\%)(Foord, } \\
\text { 1976) }\end{array}$ & NA & 9.92 & $11.6(3.4)$ & 1.17 & $50.4(6)$ & $47.2(15)$ & 0.9 岕 & $1.1(0.1)$ & $0.91(0.26)$ & 0.83 \\
\hline & Single 1g i.v. bolus; 3 (0\%)(Foord, 1976) & NA & 11.01 & $11.6(3.4)$ & 1.05 & $90.8(7.9)$ & $94.4(30.3)$ & 1.04 & $1.1(0.3)$ & $0.91(0.26)$ & 0.83 \\
\hline & $\begin{array}{l}\text { Single } 1.5 \mathrm{~g} \text { i.v. infusion ; } 23 \\
(22 \%)(\text { Kagedal et al., } 2007)\end{array}$ & NA & 12.10 & $11.2(3.3)$ & 0.93 & 124 & $145(44)$ & 1.17 & 1.3 & $0.91(0.25)$ & 0.70 \\
\hline & $\begin{array}{l}\text { Single } 0.75 \mathrm{~g} \text { i.v. bolus; } 3 \\
(0 \%)\left(O^{\prime} \text { Callaghan and Harding, 1977) }\right.\end{array}$ & NA & 9.52 & $11.1(3)$ & 1.17 & 78.8 & $72.5(19.4)$ & 0.92 & 1.267 & $0.90(0.23)$ & 0.71 \\
\hline & $\begin{array}{l}\text { Single } 1.5 \mathrm{~g} \text { i.v. bolus; } 3 \\
(0 \%)\left(O^{\prime} \text { Callaghan and Harding, 1977) }\right.\end{array}$ & NA & 8.67 & $11.1(3)$ & 1.28 & 173 & $145(39)$ & 0.84 & 1.2 & $0.90(0.23)$ & 0.75 \\
\hline & $\begin{array}{l}\text { single } 0.75 \text { g i.v. bolus; } 10 \\
(100 \%)(\text { Philipson and Stiernstedt, } \\
1982)\end{array}$ & NA & $11.9(1.6)$ & $11.0(2.8)$ & 0.92 & $60.8(8.6)$ & $75.0(19)$ & 1.23 & $0.97(0.13)$ & $0.80(0.18)$ & 0.82 \\
\hline & Single 0.75 g i.m.; 6 (100\%)(Harding et & NA & 9.44 & $10.1(2.7)$ & 1.07 & 78.0 & $77.4(20)$ & 0.99 & 1.0 & $0.88(0.17)$ & 0.88 \\
\hline & Single 0.75 g i.m.; 6 (0\%)(Foord, 1976) & NA & 8.43 & $11.8(3.6)$ & 1.40 & 88.6 & $69.9(23.3)$ & 0.79 & NA & $0.95(0.25)$ & NA \\
\hline & Single 1 g i.m.; 5 (0\%)(Foord, 1976) & NA & 9.87 & $11.9(3.7)$ & 1.20 & 101.3 & $92.3(31)$ & 0.91 & NA & $0.93(0.25)$ & NA \\
\hline & Single 0.75 g i.m.; 12 (0\%)(O'Callaghan & NA & NA & $11.9(3.8)$ & NA & 68.0 & $69.5(22)$ & 1.02 & 1.0 & $1.0(0.24)$ & 1.00 \\
\hline
\end{tabular}




\begin{tabular}{|c|c|c|c|c|c|c|c|c|c|c|c|}
\hline & $\begin{array}{l}\text { Single } 1 \mathrm{~g} \text { i.m.; } 8 \text { (0\%) (O'Callaghan and } \\
\text { Harding, 1977) }\end{array}$ & NA & NA & 11.9 (3.8) & NA & 68.0 & $69.5(22)$ & 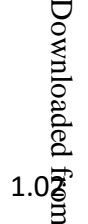 & 1.0 & $1.0(0.24)$ & 1.00 \\
\hline & $\begin{array}{l}\text { Single } 1.5 \mathrm{~g} \text { i.m.; } 4 \text { (0\%)(O'Callaghan } \\
\text { and Harding, 1977) }\end{array}$ & NA & NA & $12(3.6)$ & NA & 115 & $137(47)$ & $1.1 \overline{\bar{Z}}$ & 1.0 & $0.96(0.24)$ & 0.96 \\
\hline \multirow{4}{*}{ 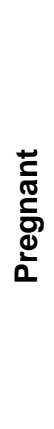 } & $\begin{array}{l}\text { Single } 0.75 \text { g i.v. bolus; } 7 \\
(100 \%) \text { (Philipson and Stiernstedt, } \\
1982)\end{array}$ & $11-35$ & $16.9(2.0)$ & 13.1 (3.7) & 0.78 & $42.0(5.2)$ & 61.4 (16.4) & \multirow{4}{*}{ 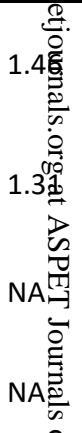 } & $0.73(0.10)$ & $0.88(0.30)$ & 1.21 \\
\hline & $\begin{array}{l}\text { Single } 0.75 \text { g i.v. bolus; } 7 \\
(100 \%)(\text { Philipson and Stiernstedt, } \\
1982)\end{array}$ & 40 & $15.5(2.1)$ & $12.9(3.0)$ & 0.83 & 46.7 (8.4) & $61.3(14.4)$ & & $0.87(0.17)$ & 1.45 & 1.67 \\
\hline & $\begin{array}{l}\text { Single } 1.5 \mathrm{~g} \text { i.v. bolus; } 13(100 \%) \text { (Holt et } \\
\text { al., 1994) }\end{array}$ & $38-40$ & NA & $12.8(3.0)$ & NA & NA & $123(28)$ & & NA & $1.4(0.2)$ & NA \\
\hline & $\begin{array}{l}\text { Single } 0.750 \text { g i.m.; } 22 \text { (100\%) (Craft et } \\
\text { al., 1981) }\end{array}$ & $37-40$ & NA & $13.7(3.5)$ & NA & NA & $58.3(14)$ & & *1.4 (1.1-1.9) & $* 2.0(1.2-5)$ & 1.43 \\
\hline
\end{tabular}

Results expressed as mean (SD), *mean (range), AUC: area under the concentration curve; CL: total systemic clearance:\%F: percentage of female 
Table 2. Predicted vs observed maternal and fetal parameters ratios of cefuroxime, cefazolin, and amoxicillin in the umbilical cord.

\begin{tabular}{|c|c|c|c|c|c|c|}
\hline & \multirow{2}{*}{ Study design } & \multirow{2}{*}{ GWs } & \multicolumn{4}{|c|}{$\stackrel{P}{\stackrel{0}{*}}$ Cord/Maternal } \\
\hline & & & Obs & $\frac{0}{0}$ & Pred* & Ratio \\
\hline \multirow{9}{*}{ 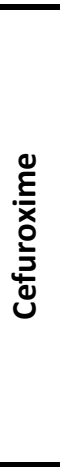 } & Single $0.75 g$ i.v. $(n=8)$ (Philipson and Stiernstedt, 1982) & 40 & $1.1 \pm 2.2(0.3-6)^{1}$ & \multirow{9}{*}{ 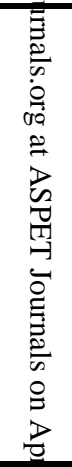 } & $0.83(0.6-1.0)$ & 0.8 \\
\hline & Multiple 1.5g i.v. t.i.d. (n=15)(De Leeuw et al., 1993) & $27-34$ & $1.1^{2}$ & & $0.84(0.7-1.0)$ & 0.8 \\
\hline & Single 0.75 g i.m. ( $n=10$ natural labour) (Craft et al., & $37-40$ & $0.83(0.42-1.08)$ & & $0.82(0.62-1.0)$ & 1.0 \\
\hline & 1981) & $37-40$ & $0.50(0.18-0.75)$ & & $0.82(0.62-1.0)$ & 1.6 \\
\hline & Single $0.75 \mathrm{~g}$ i.m. ( $n=12$ C-section) (Craft et al., 1981) & & & & & \\
\hline & Single $0.75 g$ i.v. $(n=26)$ (Holt et al., 1994) & $38-40$ & 0.45 & & $0.77(0.6-1.0)$ & 1.7 \\
\hline & Single $1.5 g$ i.v. ( $n=18)$ - control group (Lalic-Popovic et al., & 40 & $0.71 \pm 0.46$ & & $0.77 \pm 0.10$ & 1.1 \\
\hline & 2016) & 40 & $0.59 \pm 0.40$ & & $0.77 \pm 0.10$ & 1.3 \\
\hline & $\begin{array}{l}\text { Single } 1.5 \mathrm{~g} \text { i.v. }(\mathrm{n}=21) \text { - hypertensive group (Lalic-Popovic } \\
\text { et al., 2016) }\end{array}$ & & & & & \\
\hline \multirow{4}{*}{ 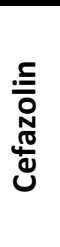 } & Single $2 g$ i.v. $(n=7)($ Brown et al., 1990) & $23-32$ & $0.19(0.03-0.54)$ & \multirow{4}{*}{$\begin{array}{l}\vec{E} \\
\tilde{\alpha} \\
\tilde{N} \\
\tilde{N} \\
\omega\end{array}$} & $0.15(0.10-0.25)$ & 0.80 \\
\hline & Single $1 g$ i.v. bolus ( $n=20)$ (Elkomy et al., 2014) & $36-40$ & $0.41(0.21-1.45)^{3}$ & & $0.36(0.23-0.61)^{3}$ & 0.88 \\
\hline & Single 2g i.v.; $(n=65)($ Kram et al., 2017$)$ & 38.9 & $0.47^{4}$ & & $0.60(0.28-1.56)^{4}$ & 1.3 \\
\hline & Single 3g i.v.; ( $n=19)$ (Kram et al., 2017) & 38.5 & $0.62^{4}$ & & $0.62(0.29-1.34)^{4}$ & 1.0 \\
\hline \multirow{4}{*}{ 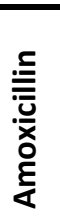 } & Single 1000 g i.v. (n=35)(Zareba-Szczudlik et al., 2016) & $37-40$ & $1.3^{5}$ & & $2.1(1.1-5.3)^{5}$ & $1.6^{5}$ \\
\hline & & & & & $0.91(0.78-1.12)^{6}$ & 0.7 \\
\hline & Single 500 mg PO (n=30)(Zareba-Szczudlik et al., 2017) & $37-40$ & 0.4 & & $1.2(0.8-1.2)^{5}$ & 3.0 \\
\hline & & & & & $0.93(0.75-1.06)^{6}$ & 2.3 \\
\hline
\end{tabular}

*Predicted Cord/Maternal ratio were calculated based on the AUCt for the predicted concentration profiles. Results expressed as mean (range), i.v.: intravenous, i.m.: intramuscular, t.i.d.: three times daily

${ }^{1}$ Geometric Mean $\pm S D\left(\right.$ range), ${ }^{2}$ Geometric Mean for $C_{8 h},{ }^{3}$ Median (range), ${ }^{4}$ Mean for $C_{1.8 h},{ }^{5}$ Mean (Range) for $C_{2.0 h},{ }^{6}$ Mean (Range) for AUC $C_{\text {INF }}$ 
Table 3. Predicted vs observed pharmacokinetic parameters of cefazolin in non-pregnant subjects and during pregू⿹

\begin{tabular}{|c|c|c|c|c|c|c|c|c|c|c|c|}
\hline & \multirow{2}{*}{ Study design } & \multirow{2}{*}{ GWs } & \multicolumn{3}{|l|}{ CL (L/h) } & \multicolumn{2}{|c|}{ AUC (mg. h/L) } & \multirow{2}{*}{$\frac{\stackrel{8}{\Xi}}{\text { Rầtio }}$} & \multicolumn{3}{|c|}{ Half-life (h) } \\
\hline & & & Obs & Pred & Ratio & Obs & Pred & & Obs & Pred & Ratio \\
\hline \multirow{11}{*}{ 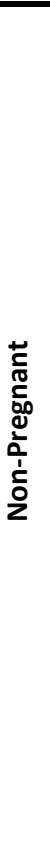 } & $\begin{array}{l}\text { Single } 2 \text { g i.v.; 7M (Smyth et al., } \\
\text { 1979) }\end{array}$ & NA & 3.58 & $4.16(1.32)$ & 1.16 & $559(93)$ & 524 (149) & 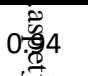 & $2.0(0.3)$ & $1.5(0.4)$ & 0.75 \\
\hline & $\begin{array}{l}\text { Single } 3 \text { g i.v.; 7M (Smyth et al., } \\
\text { 1979) }\end{array}$ & NA & 4.42 & $4.16(1.32)$ & 0.94 & $679(123)$ & 786 (223) & 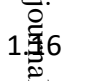 & $2.0(0.2)$ & $1.5(0.4)$ & 0.75 \\
\hline & $\begin{array}{l}\text { Single 4g i.v.; } 7 M \text { (Smyth et al., } \\
\text { 1979) }\end{array}$ & NA & 4.56 & $4.16(1.32)$ & 0.91 & $878(146)$ & 1049 (297) & $1 \stackrel{\bar{\omega}}{199}$ & $1.9(0.2)$ & $1.9(0.47)$ & 1.00 \\
\hline & $\begin{array}{l}\text { Multiple } 4 \mathrm{~g} \text { b.i.d. Day 5; } 7 \mathrm{M} \\
\text { (Smyth et al., 1979) }\end{array}$ & NA & 5.1 & $4.81(1.3)$ & 0.94 & $778(88)$ & $1041(291)$ & $1 \stackrel{2}{\stackrel{3}{3} 4}$ & $1.8(0.2)$ & $1.9(0.47)$ & 1.05 \\
\hline & $\begin{array}{l}\text { Multiple 4g b.i.d. Day 10; 7M } \\
\text { (Smyth et al., 1979) }\end{array}$ & NA & 4.94 & $4.81(1.3)$ & 0.97 & $810(112)$ & $1041(291)$ & 1. & $1.8(0.2)$ & $1.9(0.47)$ & 1.06 \\
\hline & $\begin{array}{l}\text { Single } 1 \mathrm{~g} \text { ( } 2 \text { min inf); 17M (Rattie } \\
\text { and Ravin, 1975) }\end{array}$ & NA & 3.8 & $4.27(1.43)$ & 1.12 & 264 & $258(78)$ & $0 . \overline{\underline{\underline{G}}} 8$ & 1.4 & $1.5(0.4)$ & 1.07 \\
\hline & $\begin{array}{l}\text { Single } 2 \mathrm{~g}(10 \mathrm{~min} \text { - inf); } 6 \mathrm{M} \text { (Brown } \\
\text { et al., 1993) }\end{array}$ & NA & $\begin{array}{l}4.96 \\
<2.68^{\mathrm{a}}>\end{array}$ & $\begin{array}{l}4.16(1.33) \\
<2.48(0.56)^{\mathrm{a}}>\end{array}$ & $\begin{array}{l}0.84 \\
<0.93 a>\end{array}$ & NA & $\begin{array}{l}525(151) \\
\left\langle 846(175)^{\mathrm{a}}\right\rangle\end{array}$ & $\underset{>}{N \AA}$ & $\begin{array}{l}1.6 \\
<2.7^{\mathrm{a}}>\end{array}$ & $\begin{array}{l}1.5(0.38) \\
<1.9(0.47)^{\mathrm{a}}>\end{array}$ & $\begin{array}{l}1.00 \\
<0.7^{\mathrm{a}}>\end{array}$ \\
\hline & $\begin{array}{l}\text { Single } 0.5 \mathrm{~g}(2 \mathrm{~min}-\text {-inf }) ; 6 \mathrm{~F} \\
\text { (Philipson et al., 1987) }\end{array}$ & 0 & $4.66(0.74)$ & $4.3(1.2)$ & 0.92 & $110(21)$ & $127(33)$ & 1.⿻弋乛龰 & $1.7(0.3)$ & $1.2(0.4)$ & 0.71 \\
\hline & $\begin{array}{l}\text { Single 1g bolus; } 20 \mathrm{~F} \text { (Elkomy et al., } \\
\text { 2014) }\end{array}$ & 0 & 4.12 & $4.2(1.3)$ & 1.02 & NA & 257.4 & N & NA & $1.2(0.3)$ & NA \\
\hline & $\begin{array}{l}\text { Single } 1 \text { g i.m.; } 11 \mathrm{M} \text { (Scheld et al., } \\
\text { 1981) }\end{array}$ & NA & NA & $5.1(2.1)$ & NA & $218(40)$ & $227(81)$ & 1.04 & $2.1(0.5)$ & $1.5(0.4)$ & 0.72 \\
\hline & $\begin{array}{l}\text { Single } 1 \mathrm{~g} \text { i.m.; } 11 \mathrm{M} \text { (Kirby and } \\
\text { Regamey, 1973) }\end{array}$ & NA & NA & $5.0(2.1)$ & NA & NA & $229(83)$ & NA & 1.8 & $1.5(0.4)$ & 0.84 \\
\hline \multirow{6}{*}{ 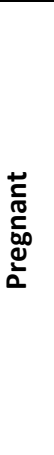 } & $\begin{array}{l}\text { Single 0.5g i.v.; 6F (Philipson et al., } \\
\text { 1987) }\end{array}$ & $19-33$ & $7.3(3.0)$ & $6.9(2.6)$ & 0.95 & 75.7 (27.6) & $80.8(24)$ & 1.1 & $1.1(0.1)$ & $1.0(0.3)$ & 0.91 \\
\hline & $\begin{array}{l}\text { Single } 2 \mathrm{~g} \text { (30 min-inf); 49F } \\
\text { (Allegaert et al., 2009) }\end{array}$ & $17-40$ & $7.44(1.34)$ & $7.03(2.22)$ & 0.94 & $269^{b}$ & 309 (87) & 1.15 & $0.74^{b}$ & $1.25(0.37)$ & 1.69 \\
\hline & $\begin{array}{l}\text { Single } 2 \mathrm{~g} \text { i.v.; } 120 \mathrm{~F} \text { (van Hasselt } \\
\text { et al., 2014) }\end{array}$ & $17-27$ & $7.48^{b}$ & $6.94(2.7)$ & 0.93 & NA & $322(101)$ & NA & NA & $1.3(0.24)$ & NA \\
\hline & $\begin{array}{l}\text { Single } 1 \mathrm{~g} \text { or } 2 \mathrm{~g} ; 30 \mathrm{~F} \text { (van Hasselt } \\
\text { et al., 2014) }\end{array}$ & $28-40$ & $7.54^{b}$ & $6.8(2.3)$ & 0.90 & NA & 266 (107) & NA & NA & $1.3(0.25)$ & NA \\
\hline & $\begin{array}{l}\text { Single } 1 \mathrm{~g} \text { bolus; } 20 \mathrm{~F} \text { (Elkomy et } \\
\text { al., 2014) }\end{array}$ & $36-40$ & $7.18(0.56)$ & $6.3(1.8)$ & 0.90 & NA & $170(44)$ & NA & NA & $1.2(0.2)$ & NA \\
\hline & $\begin{array}{l}\text { Single } 2 \mathrm{~g} \text { ( } 7 \mathrm{~min}-\mathrm{inf}) ; 32 \mathrm{~F} \\
\text { (Grupper et al., 2017) }\end{array}$ & $39 \mathrm{GWs}$ & $7.38(5.34)$ & $9.25(2.58)$ & 1.25 & 271 & $232(60)$ & 0.86 & NA & $1.1(0.3)$ & NA \\
\hline
\end{tabular}


Values are given as mean(SD). Simulated population size for each study was 20 x actual study size; AUC: area uñ乛̣der the concentration curve; CL: Systemic clearance, M: male, F: female, i.v.: intravenous, i.m.: intramuscular, b.i.d.: twice daily, inf: (duration) infusion; $\left\langle\xi\right.$ : values in the presence of probenecid, ${ }^{b}$ values were calculated using the reported PK parameter means.

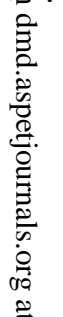

Table 4 Predicted vs observed PK parameters of amoxicillin in non-pregnant subjects and during pregnancy after i iatravenous or oral administration.

\begin{tabular}{|c|c|c|c|c|c|c|c|c|c|c|c|}
\hline & \multirow{2}{*}{$\begin{array}{l}\text { Study design; Population n } \\
\text { (\%F) }\end{array}$} & \multirow{2}{*}{ GWs } & \multicolumn{3}{|c|}{$\mathrm{CL}(\mathrm{L} / \mathrm{h})$} & \multicolumn{3}{|c|}{ AUC (mg. h/L) } & \multicolumn{3}{|c|}{ Half-life (h) } \\
\hline & & & Obs & Pred & Ratio & Obs & Pred & Raģ⿻ & Obs & Pred & Ratio \\
\hline \multirow{11}{*}{ 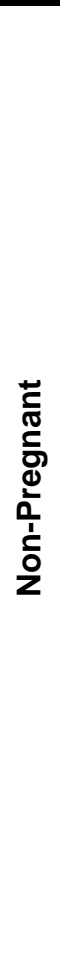 } & 0.25 g i.v. bolus; $7(0 \%)$ (Dalhoff & NA & 12.2 & $14.8(3.7)$ & 1.30 & $20.57(3.64)$ & $18.1(4.9)$ & $0.8 \%$ & NA & $1.29(0.47)$ & NA \\
\hline & $\begin{array}{l}0.5 \text { g i.v. infusion } ; 7(0 \%) \\
\text { (Dalhoff and Koeppe, 1982) }\end{array}$ & NA & 11.7 & $14.8(3.7)$ & 1.34 & $42.56(6.4)$ & $36.19(9.83)$ & $\begin{array}{r}0.88 \\
? \\
0 \\
\end{array}$ & NA & $1.29(0.47)$ & NA \\
\hline & $\begin{array}{l}1 \mathrm{~g} \text { i.v. bolus ; } 7 \text { (0\%) (Dalhoff } \\
\text { and Koeppe, 1982) }\end{array}$ & NA & 12.4 & $14.8(3.7)$ & 1.19 & $80.57(9.75)$ & 72.4(19.7) & $\begin{array}{r}0.980 \\
\text { No }\end{array}$ & NA & $1.29(0.47)$ & NA \\
\hline & $\begin{array}{l}0.25 \text { g i.v. bolus; } 7(0 \%) \text { (Hill et } \\
\text { al., 1980) (0\%)(Hill et al., 1980) }\end{array}$ & NA & 15.2 & $14.8(3.7)$ & 0.97 & $16.5(1.3)$ & $18.1(4.9)$ & 1.10 & $1.19(0.03)$ & $1.29(0.47)$ & 1.08 \\
\hline & $\begin{array}{l}0.5 \mathrm{~g} \text { i.v. bolus; } 7 \text { (0\%)(Hill et al., } \\
1980)\end{array}$ & NA & 16.0 & $14.8(3.7)$ & 0.93 & $31.3(1.7)$ & $36.2(9.8)$ & 1.16 & $1.25(0.02)$ & $1.29(0.47)$ & 1.03 \\
\hline & $\begin{array}{l}1 \mathrm{~g} \text { i.v. bolus; } 7 \text { (0\%)(Hill et al., } \\
1980)\end{array}$ & NA & 15.5 & $14.8(3.7)$ & 0.95 & $64.6(4.7)$ & $72.4(19.7)$ & 1.12 & $1.11(0.02)$ & $1.29(0.47)$ & 1.16 \\
\hline & $\begin{array}{l}2 \text { g i.v. } 28 \text {-min inf; } 7 \text { (0\%)(Hill et } \\
\text { al., 1980) }\end{array}$ & NA & 15.4 & $15.1(3.9)$ & 0.98 & $130(10.7)$ & 142(39) & 1.09 & $1.19(0.05)$ & $1.19(0.32)$ & 1.00 \\
\hline & $\begin{array}{l}5 \mathrm{~g} \text { i.v. } 28 \text {-min inf; } 7 \text { (0\%)(Hill et } \\
\text { al., 1980) }\end{array}$ & NA & 12.9 & $15.1(3.9)$ & 1.17 & $386.3(32.2)$ & $354(98)$ & 0.92 & $1.32(0.04)$ & $1.19(0.32)$ & 0.90 \\
\hline & $\begin{array}{l}\text { 0.5g i.v. bolus; } 9 \\
(22 \%)(\text { Arancibia et al., } 1980)\end{array}$ & NA & $13.5(3.5)$ & $15.8(2.6)$ & 1.17 & $37.0(9.7)$ & $36.6(7.1)$ & 0.86 & $1.08(0.28)$ & $0.83(0.16)$ & 0.74 \\
\hline & $\begin{array}{l}4 \text { g i.v. } 5 \text {-min inf; } 12 \\
(50 \%)(\text { Adam et al., } 1983 \text { ) }\end{array}$ & NA & $9.46(1.4)$ & $14.9(3.8)$ & 1.57 & $423(62)$ & $286.4(75.5)$ & 0.68 & $1.11(2.2)$ & $1.54(0.8)$ & 1.39 \\
\hline & 1g PO; 12(50\%)(Prevot et al., & NA & NA & $29.9(12.2)$ & NA & $47.6(12)$ & $38.7(14.8)$ & 0.81 & $1.3(0.2)$ & $1.35(0.38)$ & 1.04 \\
\hline
\end{tabular}




\begin{tabular}{|c|c|c|c|c|c|c|c|c|c|c|c|}
\hline & $\begin{array}{l}\text { 1g PO; } 8 \text { (0\%)(Westphal et al., } \\
\text { 1991) }\end{array}$ & NA & 33.7 & $31.3(12.0)$ & 0.93 & $29.72(5.3)$ & $36.4(13.3)$ & 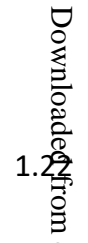 & NA & $1.42(0.4)$ & NA \\
\hline & $\begin{array}{l}0.25 \mathrm{~g} \text { PO; } 8(0 \%) \text { (Zarowny et al., } \\
1974 \text { ) }\end{array}$ & NA & 27.3 & $31.3(12.0)$ & 1.15 & $9.17(1.70)$ & $9.45(3.46)$ & 1. & $1.05(0.30)$ & $1.42(0.4)$ & 1.35 \\
\hline & $\begin{array}{l}0.5 \mathrm{~g} \text { PO; } 12(50 \%) \text { (Pires de } \\
\text { Abreu et al., 2003) }\end{array}$ & NA & 21.0 & 27.8 & 1.32 & 23.8 & 18 & $0 . \sqrt[260]{0}$ & 1.2 & 1.33 & 1.11 \\
\hline & $\begin{array}{l}0.5 \mathrm{~g} \text { PO; } 12(50 \%) \text { (Adam et al., } \\
1983 \text { ) }\end{array}$ & NA & 25.8 & $31.3(12.3)$ & 1.21 & $19.4(4.5)$ & $19.1(7.3)$ & 0.9 .98 & $0.88(0.18)$ & $1.37(0.39)$ & 1.56 \\
\hline & $\begin{array}{l}0.5 \mathrm{~g} \text { PO; } 16 \text { (100\%)(Andrew et } \\
\text { al., 2007) }\end{array}$ & NA & $28.8(16)$ & $28.1(11.1)$ & 0.98 & $20.4(6.6)$ & $20.4(7.5)$ & $\begin{array}{l}1.0 \overline{0} \\
\bar{n} \\
\bar{n}\end{array}$ & $1.6(0.2)$ & $1.32(0.37)$ & 0.83 \\
\hline \multirow{5}{*}{ 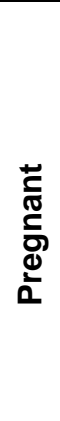 } & 15-min inf $1 \mathrm{~g} ; 34$ (Muller et al., & $30-40$ & 21.1(19.6 - & $19.23(12.3-$ & 0.91 & 47.4 & 55.4 & 1.17 & $1.2(0.2)$ & $1.3(0.3)$ & 1.08 \\
\hline & $\begin{array}{l}\text { 30-min inf } 2 \mathrm{~g} ; 34 \text { (Muller et al., } \\
2008 \mathrm{~b} \text { ) }\end{array}$ & $30-40$ & $\begin{array}{l}21.1(19.6- \\
23)\end{array}$ & $\begin{array}{l}19.23(12.3- \\
28.2)\end{array}$ & 0.91 & 94.8 & 111 & 1.高 & $1.2(0.2)$ & $1.3(0.3)$ & 1.08 \\
\hline & $\begin{array}{l}1 \mathrm{gm} \inf \text { then } 2 \mathrm{~g} \text { inf (Muller et } \\
\text { al., 2008a) }\end{array}$ & $29-37$ & 22.8 & $19.5(5.0)$ & 0.86 & NA & NA & NA & 1.1 & $0.92(0.2)$ & 0.84 \\
\hline & $\begin{array}{l}0.5 \mathrm{~g} \text { PO; } 16 \text { (100\%)(Andrew et } \\
\text { al., 2007) }\end{array}$ & $18-22$ & $35.5(8.5)$ & $35.1(14.1)$ & 0.99 & $15.2(5.6)$ & $16.3(6.0)$ & $1.0 \%$ & $1.2(0.5)$ & $1.32(0.36)$ & 1.1 \\
\hline & $\begin{array}{l}0.5 \mathrm{~g} \text { PO; } 16(100 \%) \text { (Andrew et } \\
\text { al., 2007) }\end{array}$ & $30-34$ & $34.5(5.9)$ & $35.3(13.6)$ & 1.02 & $14.9(2.8)$ & $16.1(5.7)$ & 1.08 & $1.3(0.2)$ & $1.42(0.3)$ & 1.1 \\
\hline
\end{tabular}

Results expressed as mean (SD), *mean (range), AUC: area under the concentration curve; PO: oral, CL: total systemic clearance. \%F: percentage of female 


\section{Declarations}

Funding: No funding was received for the preparation of this study.

Conflict of interest: All authors are full-time employees of Certara UK Limited, Simcyp

Division. The activities of Certara are supported by a consortium of pharmaceutical companies. The Simcyp Simulator is freely available, following completion of the training workshop, to approved members of academic institutions and other not-for-profit organizations for research and teaching purposes.

Ethical approval Not applicable.

Consent to participate Not applicable.

Availability material Not applicable.

Consent for publication Not applicable.

Code availability Not applicable 


\section{Fig_1}

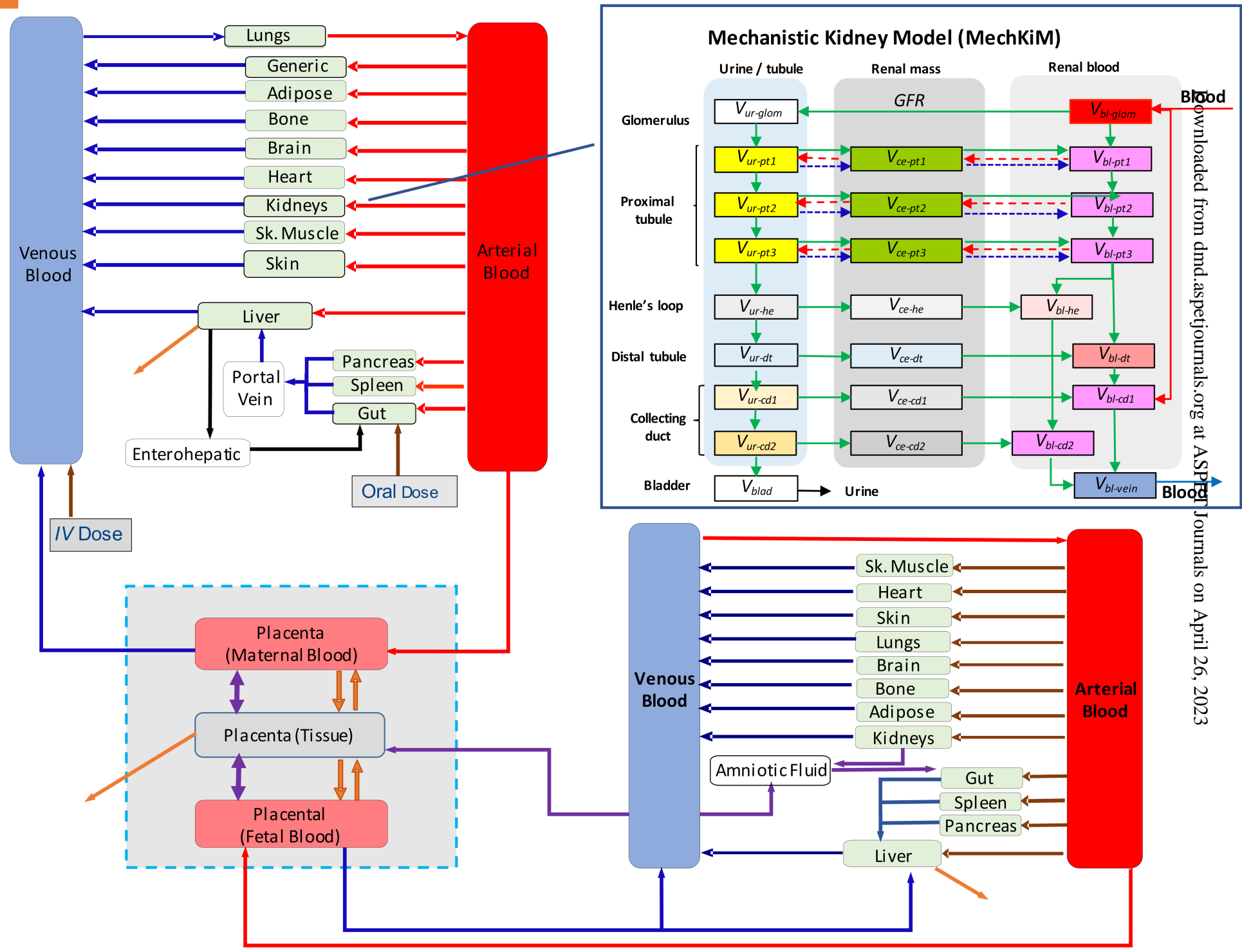


Fig. 2b
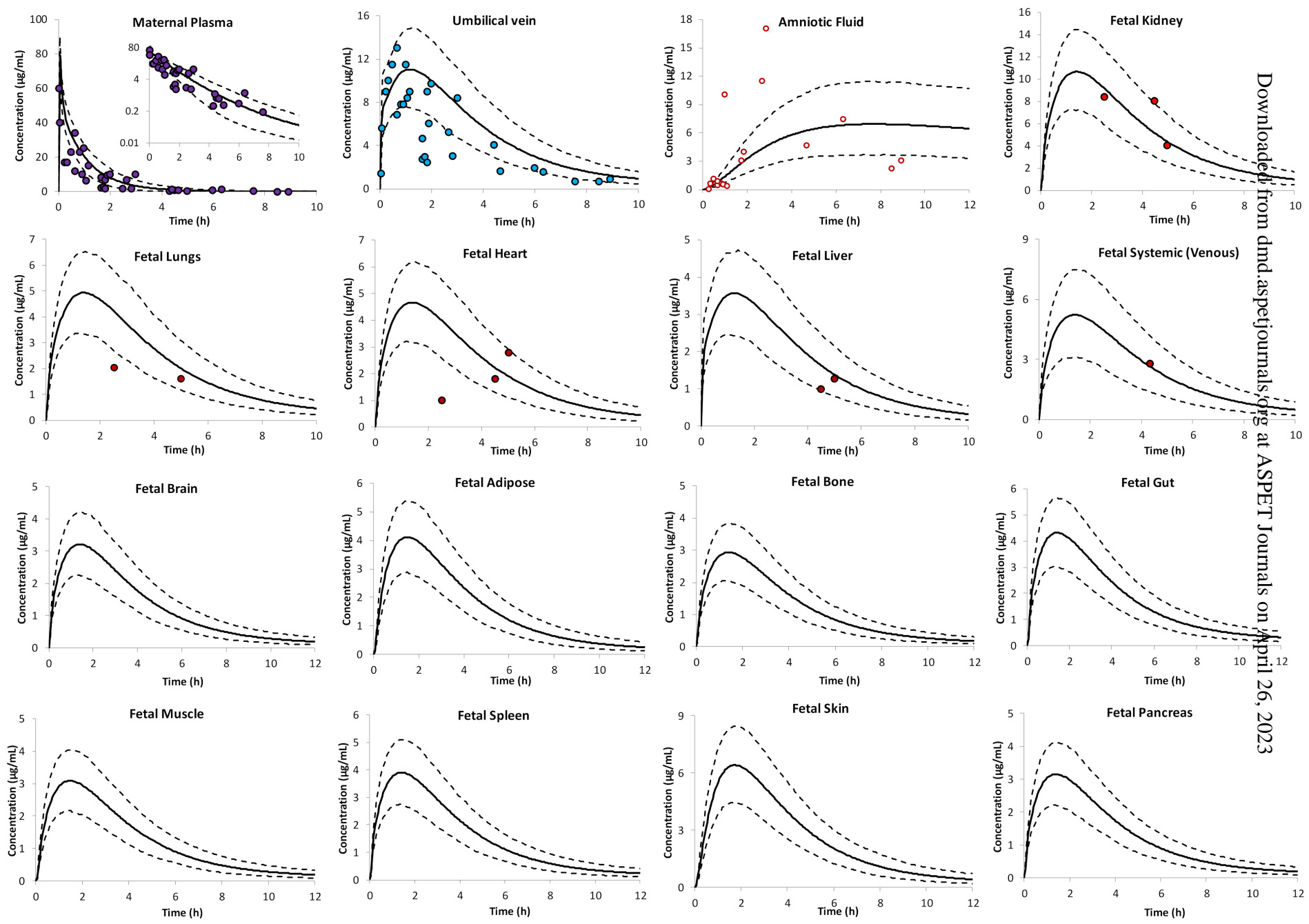

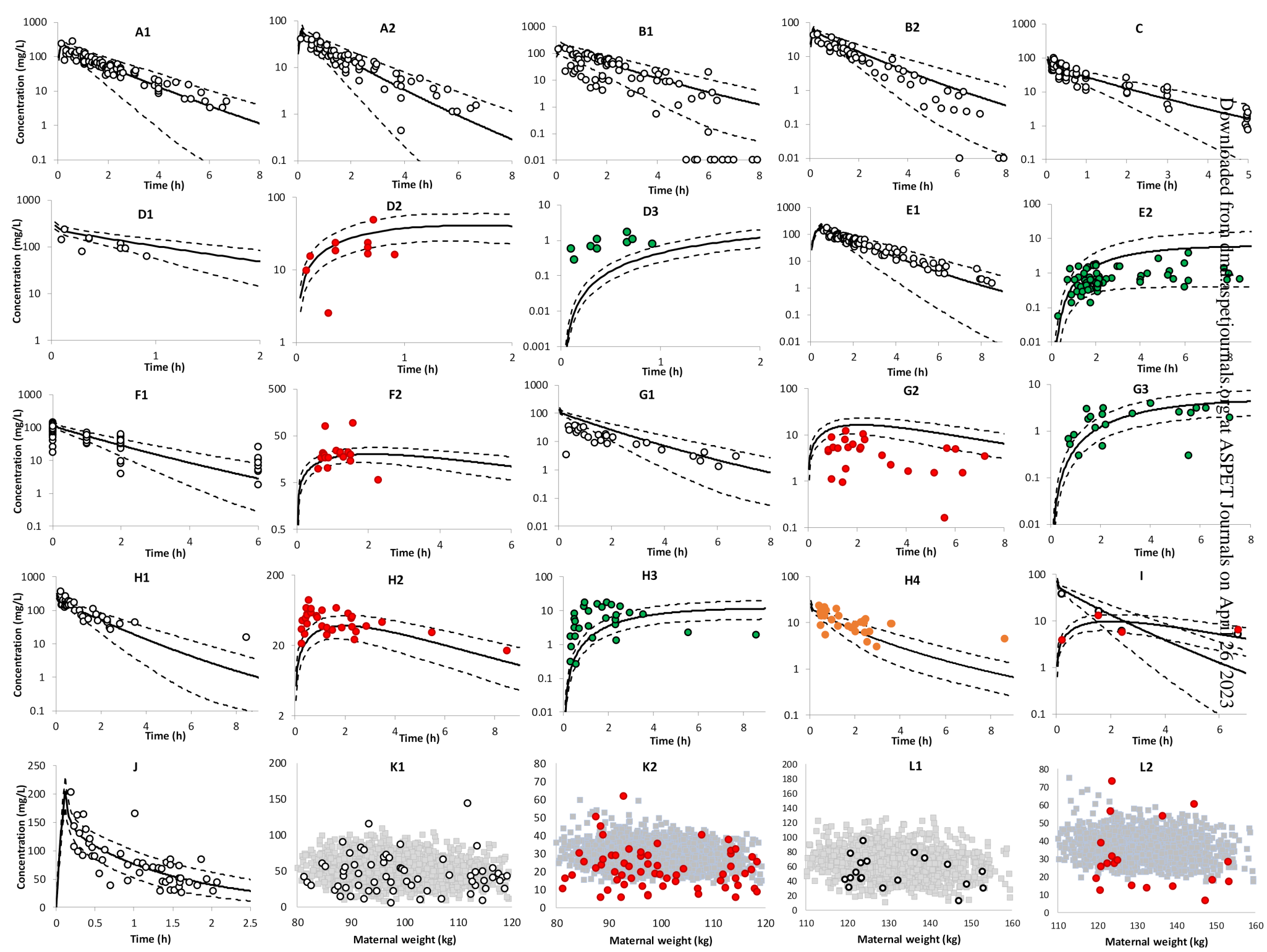
Fig. Bb
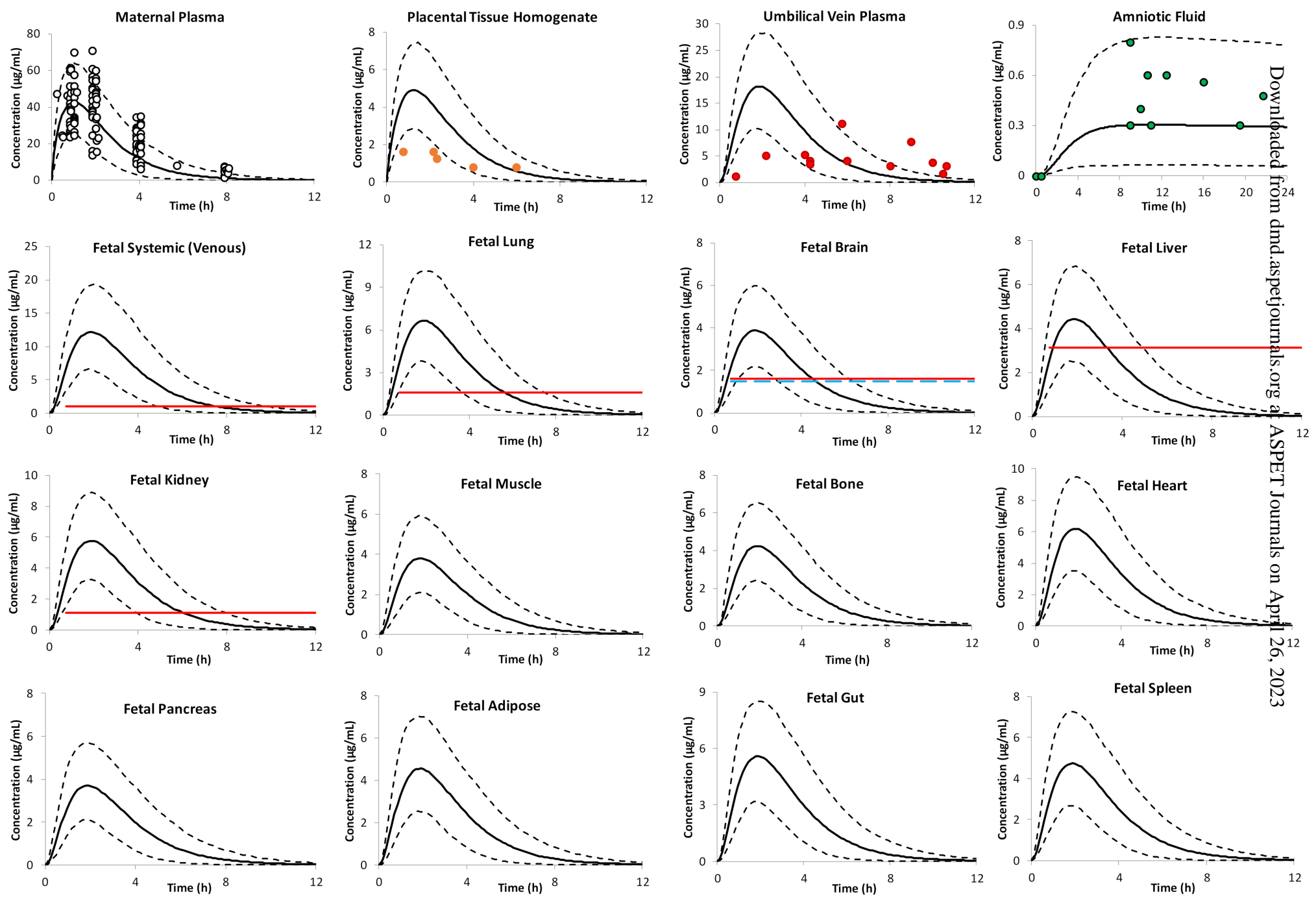
Fig 4
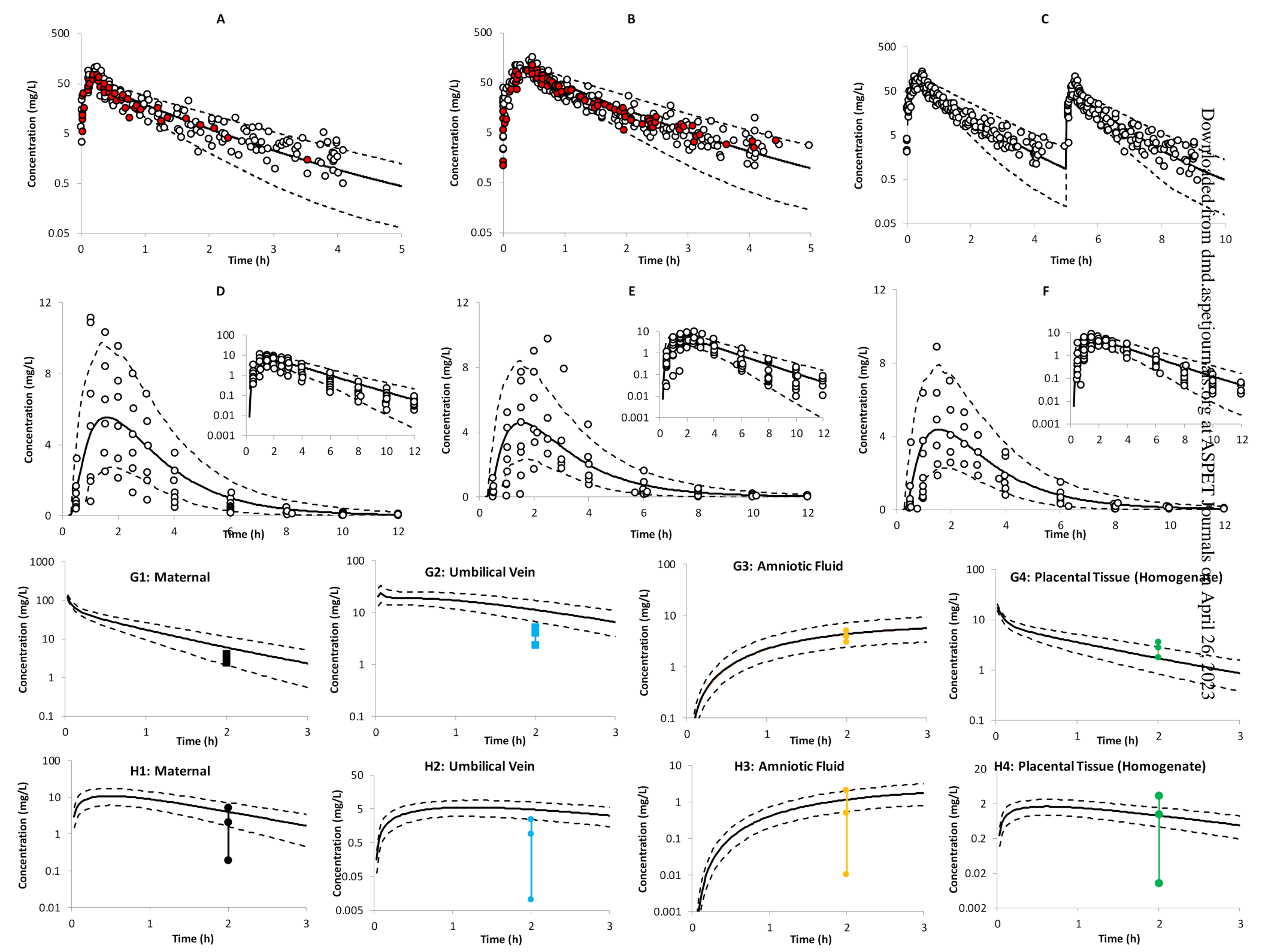